\title{
A GLOBAL VIEW OF CROSS-BORDER MIGRATION
}

\author{
Julian di Giovanni \\ Universitat Pompeu Fabra \\ and Barcelona GSE \\ Francesc Ortega \\ Queens College-CUNY
}

\begin{abstract}
This paper evaluates the global welfare impact of observed levels of migration using a quantitative multi-sector model of the world economy calibrated to aggregate and firm-level data. Our framework features cross-country labor productivity differences, international trade, remittances, and a heterogeneous workforce. We compare welfare under the observed levels of migration to a no-migration counterfactual. In the long run, natives in countries that received a lot of migrationsuch as Canada or Australia - are better off due to greater product variety available in consumption and as intermediate inputs. In the short run, the impact of migration on average welfare in these countries is close to zero, while the skilled and unskilled natives tend to experience welfare changes of opposite signs. The remaining natives in countries with large emigration flows—such as Jamaica or El Salvador-are also better off due to migration, but for a different reason: remittances. The welfare impact of observed levels of migration is substantial, at about 5\% to $10 \%$ for the main receiving countries and about $10 \%$ in countries with large incoming remittances. (JEL: F12, F15, F22, F24)
\end{abstract}

\section{Introduction}

International migration has risen steadily over the last three decades. By the 2000s, substantial fractions of the total population in many receiving countries were foreignborn. For instance, immigrants account for $8 \%-12 \%$ of the population in several G7 countries such as the United States, the United Kingdom, and France, and some 20\% of the population in other wealthy countries such as Australia, Canada, and New

\footnotetext{
The editor in charge of this paper was Fabrizio Zilibotti.
}

Acknowledgments: We are grateful to the editor, anonymous referees, Antonio Ciccone, Frédéric Docquier, Luca Opromolla, Giovanni Peri, and seminar and conference participants at various institutions for helpful suggestions, and to Lin Ma and Rishi Sharma for excellent research assistance. Di Giovanni is a Research Associate at CREI, and a Research Fellow of the CEPR. Levchenko is a Research Associate at NBER, and a Research Fellow of the CEPR.

E-mail: julian.digiovanni@upf.edu (di Giovanni); alev@umich.edu (Levchenko); fortega@qc.cuny.edu (Ortega) 
Zealand. By the same token, some developing countries have lost a substantial fraction of their population to emigration. Emigrants account for some $10 \%$ of the population of Mexico, and as much as 20\%-30\% in smaller countries such as El Salvador or Jamaica.

The sheer scale of the cross-border movements of people has led to a growing interest in understanding their welfare effects. However, compared to the attention paid to the welfare analysis of international trade, very few estimates of the welfare effects of international migration are available. This paper provides a quantitative assessment of the global welfare impact of the observed levels of migration on both origin and destination countries, taking explicitly into account the consequences of international trade and remittances. Our multi-country general equilibrium model is calibrated to match the world income distribution and world trade patterns. It incorporates several first-order features of the world economy that are important for obtaining reliable estimates of the welfare impact of migration. First, we calibrate labor productivity differences between and within countries. In order to develop reliable estimates of migrants' impact on the host economies, our framework accounts for a great deal of worker heterogeneity, with worker productivity varying by skill level, country of origin, and country of residence. In addition, we match the levels of remittances observed in the data. Remittances transfer some of the gains from the increased productivity of migrants back to the natives that remained in the home country.

Second, our model incorporates the insights of the recent literature on firm heterogeneity under monopolistic competition (e.g., Melitz 2003). In recent years, a great deal of evidence has shown that these models are highly successful at replicating both the key macro features (total trade flows, the gravity relationship) and key micro features (firm size distributions, systematically larger exporters) of the economy, making them especially suitable for quantitative analysis. Economically, the key mechanism linking migration and welfare in this framework is product variety. Inflows of immigrants increase market size, and thus the range of varieties available for consumption and as intermediate inputs. Importantly, in the presence of large labor productivity differences between countries, the impact of migration on equilibrium variety depends not only on changes in population, but also the size of the productivity gap between source and destination countries.

Third, we take explicit account of the role of goods trade in affecting the gains from migration. In our model an increase in a country's market size due to immigration will affect other countries through an increase in export variety. To capture the quantitative importance of this effect, the model features both traded and nontraded sectors with intermediate input linkages between the two, and matches the overall levels of goods trade relative to GDP. The model is solved on a sample of 60 developed and developing countries comprising some $98 \%$ of world GDP, taking into account all the multilateral trade relationships between them.

Finally, we distinguish between the short-run and the long-run impact of migration. In the short-run equilibrium, the set of potential varieties available in the economy is fixed, and thus it corresponds to the framework of Chaney (2008) and Eaton, Kortum, and Kramarz (2011). In this case, migration has an impact on product variety by affecting the entry and exit decisions of only the marginal firms (i.e., those near the 
productivity cutoff for operating a firm). Since these are the least productive firms in the economy, their economic impact is very limited. In the long-run equilibrium, the set of potential varieties will change in response to migration to dissipate net aggregate profits (free entry) as in Krugman (1980) and Melitz (2003). Because some of those new firms will be quite productive, they can have a large impact on welfare. Thus, the difference in the welfare impact of migration between the short and the long run depends crucially on the relative productivity of the marginal firms compared to the inframarginal ones. Our quantitative analysis calibrates the key parameters of the model that determine equilibrium variety in both the short and the long run: relative country size and the firm size distribution. ${ }^{1}$

The main use of our calibrated model is to compute welfare in the baseline under the observed levels of bilateral migration and in the counterfactual scenario in which global migration is undone. Our findings can be summarized as follows. In the long run, the average natives in practically every receiving country would have been worse off in the absence of migration, and this welfare loss increases in the observed share of the nonnative population. Natives in the countries with the largest stocks of immigrants relative to population (such as Australia, New Zealand, and Canada) have 5\%-10\% higher welfare under the current levels of migration compared to the no-migration counterfactual. This welfare effect is driven by the general equilibrium response of domestic variety. A lower population in the absence of migration implies a smaller equilibrium mass of varieties available in the home market, and thus lower per capita welfare.

In the short run, the welfare impact of immigration on the receiving countries is much smaller, at less than $0.5 \%$ on average, and not always positive. This is because the general equilibrium effect of increased variety is only of limited importance in the short run. At the same time, the welfare impacts of migration on the skilled and the unskilled are frequently of opposite signs, and tend to be an order of magnitude larger than the overall impact. Thus, in the short run, the main welfare impact of migration on receiving countries is distributional, and driven by the changes in the relative supply of skills associated with migration. This distributional impact is limited in the long run, as the increased variety effect predominates and the welfare changes of the two skill groups tend to be similar.

For the sending countries, the welfare impact on the staying natives depends on a tradeoff. Symmetrically to the main migration receiving countries, these source countries would ceteris paribus be better off without emigration because a larger labor force implies greater variety in production and consumption. However, absent emigration, there would be no remittances. For countries such as El Salvador or the

1. Our quantitative framework features a (long-run) scale effect. That is, other things equal, a larger labor force increases per capita welfare in the long run. Online Appendix B.3 presents a detailed treatment of both the relevance and the quantitative importance of the scale effect in our model. First, it reviews the existing empirical literature on the scale effect, and provides a comparison of the size and nature of the scale effect implied by our model to the available empirical estimates. Though our model is not calibrated to match the observed magnitude of the scale effect, the model-implied scale effect is in line with the existing empirical estimates. Second, it reports alternative welfare results under a weaker scale effect corresponding to the bottom of the range of estimates found in the literature. 
Philippines, where remittances account for more than $10 \%$ of GDP, the latter effect dominates and the average native stayer is about $10 \%$ better off under the current levels of migration. Underlying these results is the fact that the typical migrant moves from a low to a high TFP region, leading to an overall increase in the efficiency units of labor worldwide. Part of the welfare benefit of that reallocation is enjoyed by the native stayers through remittances. However, the remittance effect is not always larger than the general equilibrium variety effect. Some important emigration countries, such as Mexico, Trinidad and Tobago, and Turkey, would actually be 1\%-5\% better off in the no-migration counterfactual.

For the sending countries, the short-run impact tends to be similar to the long-run impact. This is because for these countries welfare changes are driven primarily by the loss of remittances, which is the first-order effect in both the short and the long run. By the same token, the distributional impact of migration is also limited in the sending countries, as the impact of emigration on the skill premium is small compared to the remittance effect.

The finding that the receiving countries are better off with immigration may seem unappealing because it appears at odds with the widespread opposition to immigration in high-income countries. However, observed opposition to migration is not evidence against our approach. First of all, even within the model, the receiving countries are better off only in the long run. In the short run, there is nothing in our model that guarantees gains from immigration. Thus, it could be that political opposition is driven by the short-run considerations. Second, our framework features distributional effects, that are especially pronounced in the short run. In many countries, the unskilled experience short-run welfare losses due to immigration, and thus would be expected to oppose it. ${ }^{2}$ Finally, the fact that restrictive migration policies are observed in the data is by no means evidence that those policies are welfare improving, much less optimal. Indeed, there is generally no presumption that observed economic policies are optimal, in any area of economic activity.

The seminal early treatment of the welfare consequences of migration is Berry and Soligo (1969). The existing literature on the quantitative welfare impact of migration has focused almost exclusively on the implications of cross-country labor productivity differences in a neoclassical framework with a fixed set of goods. Hamilton and Whalley (1984), Klein and Ventura (2007, 2009), Benhabib and Jovanovic (2012), and Docquier, Machado, and Sekkat (2012) develop analyses of this type in one-sector models without international trade. Davis and Weinstein (2002) and Kennan (2013) investigate the welfare effects of migration in the presence of laboraugmenting productivity differences in Ricardian and Heckscher-Ohlin models of trade, respectively. The key consequence of employing a neoclassical framework is that

2. For work on the determinants of immigration restrictions see Benhabib (1996), Ortega (2005, 2010), Facchini, Mayda, and Mishra (2011), or Facchini and Steinhardt (2011). For empirical work on individual attitudes toward immigration see Mayda (2006) and Facchini and Mayda (2009), and Ortega and Polavieja (2012) in the European context. 
immigration always weakly reduces the welfare of the native workers (i.e., suppliers of the labor input) in the receiving countries.

Our framework incorporates the driving force in these studies-labor productivity differences. The main departure of our analysis from the neoclassical migration literature is endogenous product variety. This is the key feature qualitatively as well as quantitatively, because it opens the possibility that immigration may improve the native workers' welfare. To our knowledge, the only existing study of migration with endogenous product variety is by Iranzo and Peri (2009a), who explore migration between Eastern and Western Europe in a two-country model. Our paper shares with Iranzo and Peri (2009a) the emphasis on market size and endogenous variety, but differs from it in several important respects. First and foremost, our model features bilateral remittances, which we show to be crucial for evaluating the overall welfare effect of migration in a number of sending countries. While both studies find that welfare in the emigration country is higher in the migration equilibrium, the mechanism is different: in Iranzo and Peri (2009a) the main reason is the increase in imported varieties, in our analysis it is mainly due to remittances. Second, our framework is implemented on 60 countries, and incorporates many important aspects of the world economy, such as heterogeneous country-pair specific trade costs, a nontraded sector, and two-way input-output linkages, among others. This allows for both greater realism, as well as a range of outcomes on how migration affects a wide variety of countries depending on their characteristics. And third, our analysis distinguishes between the short-run and the long-run effects of migration.

More broadly, our paper complements the small but growing empirical literature on the firm-level responses to migration and remittances. Lewis (2011) finds that unskilled immigration led to significantly lower rates of adoption of new automation techniques that substitute for unskilled labor. Using data on the universe of German firms, Dustmann and Glitz (2014) find that migration led to an increase in the size of firms that use the abundant factor more intensively, to a greater adoption of production technologies that rely on the more abundant factor, and to firm entry. Yang (2008) finds a positive effect of remittances on the number of household entrepreneurs in the Philippines. Our analysis shares with these papers the emphasis on the interaction between migration and firm decisions, but focuses on the general equilibrium perspective in which migration affects firm entry and exit through changes in overall size of the market and the labor force.

The rest of the paper is organized as follows. Section 2 introduces the migration and remittance data sources, and describes the basic patterns. Section 3 presents the theoretical framework, while Section 4 discusses the quantitative implementation of the model economy. Section 5 presents counterfactual experiments and the main welfare results. Section 6 discusses extensions and sensitivity, and Section 7 concludes.

\section{Migration and Remittances: Data Sources and Basic Patterns}

To construct the labor force disaggregated by skill level, origin, and destination country we rely on two sources: the aggregate migration stocks for the year 2006 from the OECD International Migration Database and the data for the year 2000 on the labor 
force for each country in the world by education level, origin, and destination produced by Docquier, Lowell, and Marfouk (2009) and Docquier et al. (2010a). The OECD International Migration Database contains information on the stocks of immigrants by both destination and origin country. We use data for 2006, the most recent year these data are available with comprehensive coverage. An important feature of these data is that they only contain information on 26 OECD destination countries. Thus, while we have data on nearly all origin countries, we only have immigration information for rich country destinations. As a result, strictly speaking, our counterfactual exercise analyzes the consequences of undoing migration to developed countries. Any migration to developing countries will be left unchanged. ${ }^{3}$

The shares of skilled individuals among migrants in 2000 (for ages 25 and above) by origin and destination country are sourced from Docquier et al. (2010a), and the shares of skilled among the native stayers from Docquier, Lowell, and Marfouk (2009). These shares are then applied to the 2006 aggregate migration stocks for each origindestination country pair. Skilled individuals are those that completed at least one year of college. ${ }^{4}$ Remittances data are sourced from Ratha and Shaw (2007).

To calibrate the parameters governing the relative demand for skilled labor in production in each country we estimate skill premia following the approach of Docquier, Özden, and Peri (2010b). First, we use the Barro and Lee (2010) data to compute the average years of education in the two skill groups (individuals with some college education and individuals without) for each country in our sample for the year 2005. Second, to compute the country skill premium we multiply the gap in average years of schooling between the two groups by the country-specific return to a year of schooling. Hendricks (2004) has collected Mincerian returns to schooling for a large set of countries that were estimated from micro data. ${ }^{6}$ The median return per

3. The OECD DIOC-E database contains information on immigrants to both developing and developed countries. The disadvantage of these data is that they are only available up to the year 2000 . We made the choice to use the most recent data, at the cost of not being able to evaluate migration into the non-OECD. The reason we took this route was the large migration inflows experienced by the European countries post-2000. For Europe in particular, using data for 2000 would mean that we are missing a large share of current migration. In the 2000 data, the receiving countries in our analysis account for $47 \%$ of the global stock of cross-border migrants. The new borders erected after the collapse of the Soviet Union are partly responsible for the high observed migration into the non-OECD. Excluding the former Soviet Union our receiving countries account for $55 \%$ of the global migrant stock.

4. There is a small discrepancy in how the two datasets define a skilled individual. Namely, a skilled native stayer is defined in Docquier, Lowell, and Marfouk (2009) as someone who completed college, rather than had some college. We do not believe this discrepancy to have a material impact on the results.

5. There is a great deal of variation in the average years of schooling among the unskilled workers across countries. In the United States the average years of schooling among individuals that did not attend college was 10.95 . The cross-country variation in this variable is from 1.01 (Mali) to 12.80 years (Czech Republic). By contrast, among the skilled the cross-country variation in the years of schooling is much smaller, ranging from 14.15 to 15.94 in the Barro and Lee (2010) data.

6. We try to use estimates based on 1995 data, which is the most recent period reported by Hendricks (2004). If the Mincerian coefficient estimate is not available for a country we follow Docquier, Özden, and Peri (2010b) and impute that value on the basis of estimates from neighboring countries with similar levels of income per capita. 
year of schooling in these data is 7.3\%, and the 10th and 90th percentiles are $4.2 \%$ and $12.6 \%$. The 10th, 50th, and 90th percentiles for the wage skill premium we obtain are $26 \%, 43 \%$, and $106 \%$.

We carry out the analysis on the sample of the largest 49 countries in the world by total GDP, plus a selection of eleven smaller countries that have experienced migration outflows of $10 \%$ or more of the native labor force. These 60 countries together cover $98 \%$ of world GDP. There is a 61st, rest-of-the-world category. We exclude the entrepôt economies of Hong Kong and Singapore, both of which have total trade well in excess of their GDP due to significant re-exporting activity, and place them into the rest-ofthe-world category. The sources and details for the other data used in the quantitative exercise are described when we discuss the calibration.

Table 1 lists the OECD countries in the sample and reports the share of immigrants (foreign-born), the share of emigrants, the counterfactual population change, the size of net remittances relative to GDP, and the share of skilled workers among stayers, immigrants, and emigrants. These are the countries for which data on immigrant stocks for 2006 are available. ${ }^{7}$ Table 2 reports the shares of emigrants and remittances as a share of GDP for the non-OECD countries. The population change in the counterfactual in the non-OECD coincides with the share of emigrants.

Several points are worth noting. First, the data reveal a great deal of dispersion in immigration and emigration shares. At one extreme there are countries such as Australia and New Zealand, where $25 \%$ of the population are foreign-born. At the other, El Salvador, Trinidad and Tobago, and Jamaica display emigration shares in the 20\%-30\% range. ${ }^{8}$ Second, some of the OECD countries have large gross stocks of both immigrants and emigrants. As a result, if migration had never taken place their population would be roughly the same (the third column). Ireland is the clearest example: its share of immigrants is $13 \%$, but the share of emigrants is $16 \%$. In a world without migration, its population would only be $3 \%$ higher.

The table also reports the net remittances in each country as a share of GDP. Negative values mean that a country is a net sender of remittances. Clearly, most OECD countries send more remittances than they receive, but the total net remittances are only a small share of GDP, ranging from $-1 \%$ (Australia) to $+1 \%$ (Portugal). In contrast, remittances are large relative to GDP for several non-OECD countries. For instance, Colombia, India, Mexico, and Nigeria report remittances of 3\% of GDP. However, these are small compared to Jamaica (20\%), Serbia and Montenegro (19.1\%), El Salvador (17.8\%), the Philippines (15.5\%) and the Dominican Republic (14.3\%). Hence, for these countries it will be important to take remittances into account when evaluating the welfare impact of migration.

7. Throughout the paper we use the shorthand "OECD" to refer to the group of the 26 countries for which immigration data are available in our database, and "non-OECD" to describe the rest of the country sample. The "OECD" group is predominantly the wealthy, net immigration countries. Formally, the Organization for Economic Cooperation and Development has additional member countries, such as Mexico and Turkey.

8. Once again, for these countries we are reporting data on emigration to OECD countries only. In the counterfactual these countries only experience a return of their emigrants, but not the exit of the immigrants residing in these countries. 


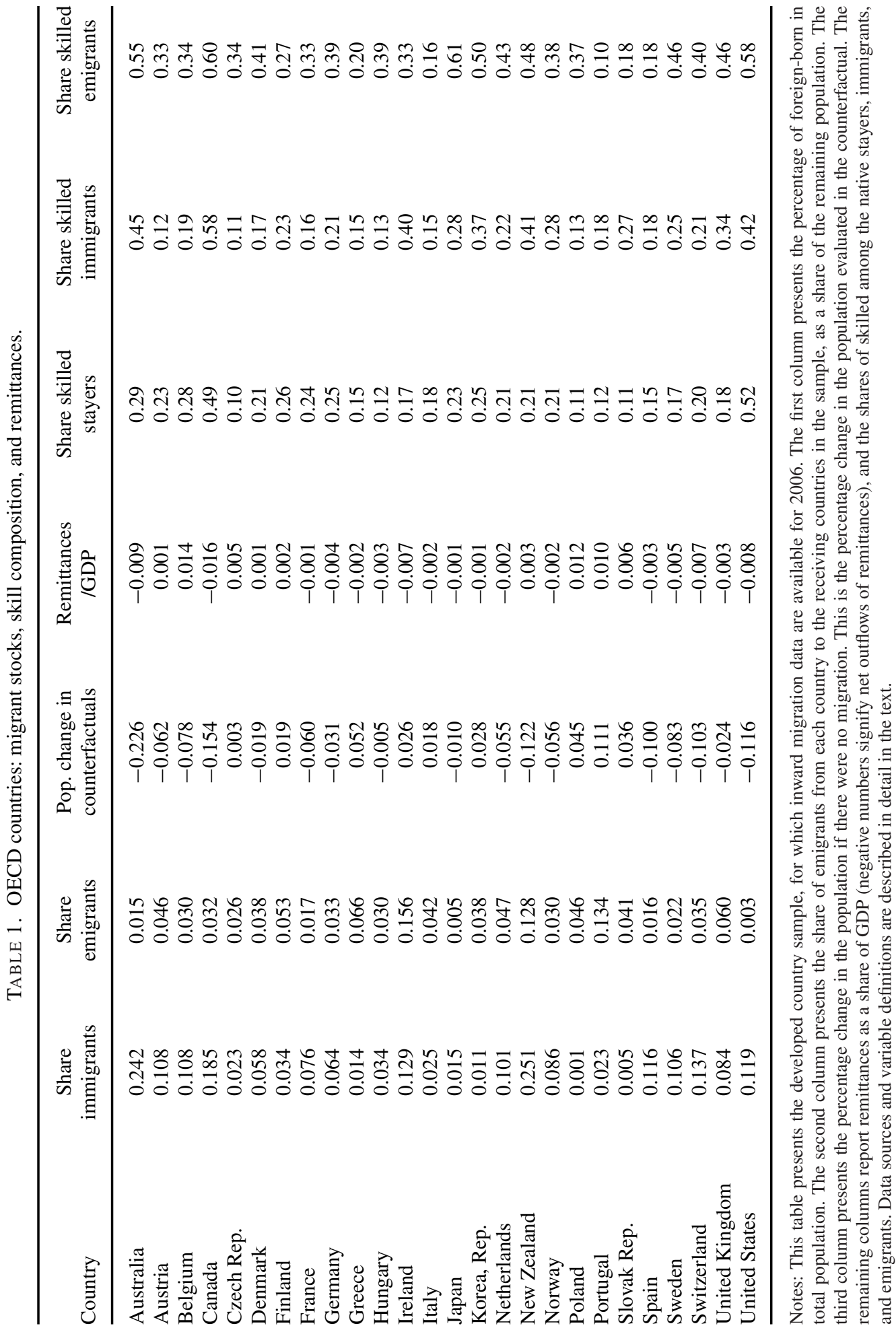


TABLE 2. Non-OECD countries: migrant stocks, skill composition, and remittances.

\begin{tabular}{|c|c|c|c|c|}
\hline Country & $\begin{array}{c}\text { Share } \\
\text { emigrants }\end{array}$ & $\begin{array}{l}\text { Remittances } \\
\text { /GDP }\end{array}$ & $\begin{array}{c}\text { Share skilled } \\
\text { stayers }\end{array}$ & $\begin{array}{c}\text { Share skilled } \\
\text { emigrants }\end{array}$ \\
\hline Algeria & 0.025 & 0.023 & 0.062 & 0.147 \\
\hline Argentina & 0.012 & -0.004 & 0.201 & 0.408 \\
\hline Belarus & 0.005 & 0.001 & 0.201 & 0.172 \\
\hline Brazil & 0.005 & 0.005 & 0.084 & 0.328 \\
\hline Bulgaria & 0.037 & 0.082 & 0.189 & 0.234 \\
\hline Chile & 0.016 & -0.002 & 0.158 & 0.403 \\
\hline China & 0.003 & 0.012 & 0.026 & 0.281 \\
\hline Colombia & 0.023 & 0.034 & 0.099 & 0.317 \\
\hline Croatia & 0.103 & 0.020 & 0.094 & 0.199 \\
\hline Dominican Rep. & 0.097 & 0.143 & 0.141 & 0.256 \\
\hline Ecuador & 0.068 & 0.050 & 0.160 & 0.266 \\
\hline Egypt, Arab Rep. & 0.004 & 0.042 & 0.104 & 0.271 \\
\hline El Salvador & 0.190 & 0.178 & 0.107 & 0.198 \\
\hline India & 0.003 & 0.030 & 0.047 & 0.318 \\
\hline Indonesia & 0.002 & 0.007 & 0.050 & 0.182 \\
\hline Iran, Islamic Rep. & 0.011 & 0.006 & 0.067 & 0.487 \\
\hline Israel & 0.021 & -0.023 & 0.241 & 0.235 \\
\hline Jamaica & 0.317 & 0.200 & 0.040 & 0.420 \\
\hline Malaysia & 0.010 & -0.006 & 0.077 & 0.352 \\
\hline Mexico & 0.107 & 0.031 & 0.111 & 0.148 \\
\hline Nigeria & 0.003 & 0.031 & 0.028 & 0.313 \\
\hline Pakistan & 0.005 & 0.044 & 0.025 & 0.231 \\
\hline Philippines & 0.030 & 0.155 & 0.159 & 0.545 \\
\hline Romania & 0.070 & 0.058 & 0.087 & 0.334 \\
\hline Russian Fed. & 0.008 & 0.001 & 0.202 & 0.309 \\
\hline Saudi Arabia & 0.004 & -0.049 & 0.093 & 0.301 \\
\hline Serbia and Mont. & 0.106 & 0.191 & 0.082 & 0.230 \\
\hline South Africa & 0.011 & 0.001 & 0.098 & 0.510 \\
\hline Thailand & 0.006 & 0.002 & 0.110 & 0.296 \\
\hline Trinidad and Tob. & 0.179 & 0.006 & 0.099 & 0.494 \\
\hline Turkey & 0.038 & -0.001 & 0.081 & 0.092 \\
\hline Ukraine & 0.019 & -0.010 & 0.162 & 0.222 \\
\hline UAE & 0.003 & - & 0.031 & 0.206 \\
\hline Venezuela & 0.011 & -0.004 & 0.185 & 0.521 \\
\hline Rest of World & 0.011 & 0.021 & 0.095 & 0.118 \\
\hline
\end{tabular}

Notes: This table presents the developing country sample, for which only outward migration data to the developed countries are available for 2006. Thus, the population change in the counterfactual coincides with the share of emigrants. The second column presents the share of emigrants from each country to the receiving countries in the sample relative the remaining population. The third column presents the percentage change in the population if there were no migration. This is the percentage change in the population evaluated in the counterfactual. The last column reports net remittances as a share of GDP (negative numbers signify net outflows of remittances). Data sources and variable definitions are described in detail in the text.

Across all origin-destination pairs, the share of skilled is 0.25 , with a standard deviation of 0.24 . There is large heterogeneity in the share of skilled among immigrants relative to the natives of the host country. For instance, US immigrants are relatively unskilled, by our measure of educational attainment: $52 \%$ of US-born stayers are 
skilled, compared to $42 \%$ of immigrants into the United States. By contrast, in Canada immigrants are relatively skilled (58\%) compared to native stayers $(49 \%)$.

\section{Theoretical Framework}

Our framework augments an otherwise standard multicountry heterogeneous firm model of production and trade with three elements that are crucial for a global quantitative assessment of the gains from migration: cross-country labor productivity differences, worker heterogeneity (across skills as well as between natives and immigrants), and remittances. We consider a monopolistically competitive setup with endogenous product variety and fixed costs of production and exporting. Production uses skilled and unskilled labor and intermediate inputs.

\subsection{Preferences, Welfare, and Love for Variety}

The world is comprised of $\mathcal{C}$ countries, indexed by $i, j=1, \ldots, \mathcal{C}$. In each country there are two broad sectors, the tradeable $T$ and the nontradeable $N$. In country $i$, a consumer with income $y_{i}$ maximizes

$$
\begin{aligned}
& \max _{\left\{y_{i}^{N}(k), y_{i}^{T}(k)\right\}}\left(\int_{J_{i}^{N}} y_{i}^{N}(k)^{\frac{\varepsilon_{N}-1}{\varepsilon_{N}}} d k\right)^{\alpha \frac{\varepsilon_{N}}{\varepsilon_{N}-1}}\left(\int_{J_{i}^{T}} y_{i}^{T}(k)^{\frac{\varepsilon_{T}-1}{\varepsilon_{T}}} d k\right)^{(1-\alpha) \frac{\varepsilon_{T}}{\varepsilon_{T}-1}} \\
& \text { subj. to: } \int_{J_{i}^{N}} p_{i}^{N}(k) y_{i}^{N}(k) d k+\int_{J_{i}^{T}} p_{i}^{T}(k) y_{i}^{T}(k) d k=y_{i},
\end{aligned}
$$

where $y_{i}^{s}(k)$ is consumption of good $k$ belonging to sector $s=N, T$ in country $i$, $p_{i}^{s}(k)$ is the price of this good, $J_{i}^{s}$ is the mass of varieties available in sector $s$ in country $i$ coming from all countries, and $\varepsilon_{s}$ is the elasticity of substitution between varieties in $s$. Standard steps yield an expression for welfare-that is, the indirect utility function —of an individual with income $y_{i}$ living in country $i$,

$$
W_{i}\left(y_{i}\right)=\frac{y_{i}}{\left(P_{i}^{N}\right)^{\alpha}\left(P_{i}^{T}\right)^{1-\alpha}},
$$

where $P_{i}^{s}$ is the ideal price index in sector $s=N, T$ in country $i$,

$$
P_{i}^{s}=\left[\int_{J_{i}^{S}} p_{i}^{s}(k)^{1-\varepsilon_{s}} d k\right]^{\frac{1}{1-\varepsilon_{s}}} .
$$

Welfare is thus simply equivalent to real income. In our model, an individual's nominal income $y_{i}$ may be composed of (i) labor income, (ii) profits of firms, and (iii) remittances, though some of these may be zero in some cases. Thus migration will have an impact on welfare through nominal income to the extent that it affects any 
of these three terms for an individual, either directly or through general equilibrium effects.

Welfare falls in the consumption price level $\left(P_{i}^{N}\right)^{\alpha}\left(P_{i}^{T}\right)^{1-\alpha}$. We assume that $\varepsilon_{s}>1, s=N, T$ (Dixit and Stiglitz 1977). The key consequence of this assumption is that preferences exhibit love for variety: holding nominal expenditure and individual goods prices fixed, the agent attains higher utility when the set of goods $J_{i}^{N}$ and $J_{i}^{T}$ available for consumption increases. Thus, to the extent that migration affects the equilibrium set of varieties available in economy $i$, it will have a welfare impact through that channel as well.

In our framework, incomes differ across individuals within each country. However, preferences are identical and homothetic, and thus admit a representative consumer. Total income $Y_{i}$ in country $i$ is the sum of labor income $w_{i} L_{i}$, net profits (if any) in the two sectors $\Pi_{i}^{N}+\Pi_{i}^{T}$, and net remittances received from abroad $R_{i}$ : $Y_{i}=w_{i} L_{i}+\Pi_{i}^{N}+\Pi_{i}^{T}+R_{i}$. Since consumer preferences are Cobb-Douglas in the CES aggregates of $N$ and $T$, it is well known that consumption expenditure on sector $N$ is equal to $\alpha Y_{i}$, and on $T$ sector, $(1-\alpha) Y_{i}$.

\subsection{Migration, Productivity, and Labor Force Composition}

Each country's labor force is composed of natives and immigrants, who can be unskilled or skilled, indexed by $e=\ell, h$ respectively. Denote by $N_{j i}^{e}$ the number of workers with skill level $e$ born in country $i$ that live in country $j$ (throughout the paper, we adopt the convention that the first subscript denotes the destination country, and the second subscript, the source). As in Trefler $(1993,1995)$, the effective labor endowment is a combination of the number of people that live in a country and their efficiency units. We build on this approach by taking explicit account of migration. Workers of skill level $e$ born in country $i$ and working in country $j$ have $A_{j i}^{e}$ efficiency units of labor. Skilled and unskilled labor are imperfect substitutes in production. Specifically, the total effective labor in country $j, L_{j}$, is given by the CES aggregate

$$
L_{j}=\left[\left(\sum_{i=1}^{\mathcal{C}} A_{j i}^{\ell} N_{j i}^{\ell}\right)^{\frac{\sigma-1}{\sigma}}+\zeta_{j}\left(\sum_{i=1}^{\mathcal{C}} A_{j i}^{h} N_{j i}^{h}\right)^{\frac{\sigma-1}{\sigma}}\right]^{\frac{\sigma}{\sigma-1}}
$$

where $\sigma$ is the elasticity of substitution between skilled and unskilled labor, $\zeta_{j}$ captures the relative importance of skilled labor in production, and, of course, the endowments of labor of each type include the native workers and their efficiency, $A_{j j}^{e} N_{j j}^{e}, e=\ell, h$.

This approach to modeling the labor force is flexible enough to capture a number of features that are important for evaluating the impact of migration. First and foremost, the framework accommodates the (large) observed cross-country labor productivity differences through differences in the $A_{j i}^{e}$. Second, skilled workers are more productive than unskilled workers. And third, conditional on skill level, immigrants may differ from native workers in how many efficiency units of labor they possess. To streamline 
notation and link the productivity parameters more transparently to observed wages, it is useful to denote the skilled-unskilled productivity gap among natives by

$$
\frac{A_{j j}^{h}}{A_{j j}^{\ell}} \equiv \mu_{j} \geq 1,
$$

and native-immigrant productivity gaps for immigrants of origin $i \neq j$ and skill level $e$ by

$$
\frac{A_{j i}^{e}}{A_{j j}^{e}} \equiv \varphi_{j i}^{e} .
$$

The latter feature allows us to account for native-immigrant wage differences conditional on educational attainment. The quantitative implementation uses several empirically relevant parameterizations of the productivity differential $\varphi_{j i}^{e}$, that can capture a number of reasons for migrant-native productivity differences, such as imperfect skill transferability or selection into migration.

Combining (3), (4), and (5), $L_{j}$ can be rewritten as

$$
L_{j}=A_{j j}\left[\left(\sum_{i=1}^{\mathcal{C}} \varphi_{j i}^{\ell} N_{j i}^{\ell}\right)^{\frac{\sigma-1}{\sigma}}+\zeta_{j}\left(\mu_{j} \sum_{i=1}^{\mathcal{C}} \varphi_{j i}^{h} N_{j i}^{h}\right)^{\frac{\sigma-1}{\sigma}}\right]^{\frac{\sigma}{\sigma-1}},
$$

where to simplify notation we relabelled the unskilled native productivity as $A_{j j}^{\ell}=$ $A_{j j}$, which can be interpreted as the economywide productivity level.

In this framework, immigrants are not the same as natives in two ways that will condition the impact of immigration. First, the share of skilled among immigrants can differ from the share of skilled among the natives. Since the skilled and the unskilled are imperfect substitutes in production, the skill composition of the immigrant population will have an effect on both the aggregate supply of labor, and on the relative wages of the skilled compared to the unskilled. Second, immigrants may have different productivity than the natives within the same skill category. This distinction has an impact on how much a given stock of foreign-born individuals changes the effective supply of labor of a particular skill level.

The baseline framework makes a number of simplifying assumptions, some of which will be relaxed in the extensions. First, immigrant and native labor of the same skill level are perfect substitutes. Online Appendix B.2 develops an extension in which immigrants and natives are imperfectly substitutable in production (Manacorda, Manning, and Wadsworth 2012; Ottaviano and Peri 2012), and shows that the main results are robust. Second, the productivity terms $A_{j i}^{e}$, while calibrated to data, are exogenous. Online Appendix B.4 relaxes this assumption and allows worker productivity to be a function of the share of skilled in the population (e.g., Jones 2002). 


\subsection{Technology}

Importantly in our framework, the sets of available goods $J_{i}^{T}$ and $J_{i}^{N}$ will differ across countries due to trade costs, and will be affected by migration. The market structure is monopolistic competition as in Melitz (2003). Each country $j$ is populated by a mass $n_{j}^{s}$ of entrepreneurs in sector $s$. Each entrepreneur $k$ in each sector $s=N, T$ and $j=1, \ldots, \mathcal{C}$ has the ability to produce a unique variety and thus has some market power. Productivity is heterogeneous: entrepreneur $k$ needs $a(k)$ input bundles to produce one unit of its good (thus more productive firms have lower $a(k)$ ). Since each entrepreneur is able to produce only one good with a particular productivity, we use the terms "entrepreneur" and "project" interchangeably.

Each entrepreneur in country $j$ and sector $s$ must incur a fixed cost $f_{j j}^{s}$ to start production, and as a result not all entrepreneurs decide to produce. We reserve the term "firm" for those entrepreneurs that actually undertake production. In sector $T$, to start exporting from country $j$ to country $i$, a firm must pay a fixed cost $f_{i j}$, and an iceberg per-unit cost of $\tau_{i j}>1$, with the iceberg cost of domestic sales normalized to one: $\tau_{j j}=1$. We assume that trade costs are infinite in the nontraded sector, and thus firms in sector $N$ only sell domestically.

Production uses skilled labor, unskilled labor, and intermediates from sectors $N$ and $T$. The production function is Cobb-Douglas in the labor, $T$, and $N$ composites. The labor composite is a CES aggregate of skilled and unskilled workers as in equation (3). The sector $s=N, T$ composites are CES aggregates of sector $s$ varieties available in the country. The minimized cost of one unit of the input bundle in country $j$ is given by

$$
c_{j}^{s}=w_{j}^{\beta_{s}}\left[\left(P_{j}^{N}\right)^{\eta_{s}}\left(P_{j}^{T}\right)^{1-\eta_{s}}\right]^{1-\beta_{s}},
$$

where $w_{j}$ is the composite wage (i.e., the price of one unit of $L$ ) in country $j$, and $P_{j}^{s}$ is the price of sector $s$ CES composite, given by equation (2). Parameters $\beta_{s}$ and $\eta_{s}$ correspond, respectively, to the share of labor in total sales and the share of nontradeable inputs in total input usage in each sector $s$.

Thus, firm $k$ in sector $s$ from country $j$ has a marginal cost $\tau_{i j} c_{j}^{s} a(k)$ of serving market $i$. Firms and consumers in country $i$ have a demand for an individual variety $k$ from sector $s$ that is given by

$$
x_{i}^{s}(k)=\frac{X_{i}^{s}}{\left(P_{i}^{s}\right)^{1-\varepsilon_{s}}} p_{i}^{s}(k)^{-\varepsilon_{s}},
$$

where $X_{i}^{s}$ denotes the total spending-final plus intermediate-on sector $s$ in country $i$.

Productivity heterogeneity combined with fixed costs of production and trade imply that not all firms will decide to serve all markets. As is well known, profit maximization yields a price that is a constant markup $\varepsilon_{s} /\left(\varepsilon_{s}-1\right)$ over marginal cost, and the total ex-post variable profits from selling to market $i$ are a constant multiple $1 / \varepsilon_{s}$ of revenue. Given the price level and total spending, there is a cutoff unit input requirement $a_{i j}^{s}$ 
above which firms in country $j$ do not serve market $i$. This cutoff is found as the unit input requirement at which the firm obtains zero profits from serving market $i$, and is given by

$$
a_{i j}^{s}=\frac{\varepsilon_{s}-1}{\varepsilon_{s}} \frac{P_{i}^{s}}{\tau_{i j} c_{j}^{s}}\left(\frac{X_{i}^{s}}{\varepsilon_{s} c_{j}^{s} f_{i j}^{s}}\right)^{\frac{1}{\varepsilon_{s}^{-1}}} .
$$

We adopt the standard assumption that firm productivity in sector $s, 1 / a$, follows a Pareto $\left(b_{s}, \theta_{s}\right)$ distribution: $\operatorname{Pr}(1 / a<y)=1-\left(b_{s} / y\right)^{\theta_{s}}$, where $b_{s}$ is the minimum value labor productivity can take, and $\theta_{s}$ regulates dispersion. It is then straightforward to show that the unit input requirement, $a$, has a distribution function $G(a)=\left(b_{s} a\right)^{\theta_{s}}$. Under this distributional assumption, we can combine equations (2) and (9) to derive expressions for the price indices:

$$
\begin{aligned}
P_{i}^{S}= & \left\{\sum_{j=1}^{\mathcal{C}} \int_{J_{i j}^{s}}\left[\frac{\varepsilon_{s}}{\varepsilon_{s}-1} \tau_{i j}^{s} c_{j}^{s} a(k)\right]^{1-\varepsilon_{s}} d k\right\}^{\frac{1}{1-\varepsilon_{s}}} \\
= & \left(\sum_{j=1}^{\mathcal{C}} n_{j}^{s} \int_{0}^{a_{i j}^{s}}\left[\frac{\varepsilon_{s}}{\varepsilon_{s}-1} \tau_{i j}^{s} c_{j}^{s} a\right]^{1-\varepsilon_{s}} d G(a)\right)^{\frac{1}{1-\varepsilon_{s}}} \\
= & \frac{1}{b_{s}}\left[\frac{\theta_{s}}{\theta_{s}-\left(\varepsilon_{s}-1\right)}\right]^{-\frac{1}{\theta_{s}}} \frac{\varepsilon_{s}}{\varepsilon_{s}-1}\left(\frac{X_{i}^{s}}{\varepsilon_{s}}\right)^{-\frac{\theta_{s}-\left(\varepsilon_{s}-1\right)}{\theta_{s}\left(\varepsilon_{s}-1\right)}} \\
& \times\left(\sum_{j=1}^{\mathcal{C}} n_{j}^{s}\left(\tau_{i j}^{s} c_{j}^{s}\right)^{-\theta_{s}}\left(c_{j}^{s} f_{i j}^{s}\right)^{-\frac{\theta_{s}-\left(\varepsilon_{s}-1\right)}{\varepsilon_{s}-1}}\right)^{-\frac{1}{\theta_{s}}}
\end{aligned}
$$

where $J_{i j}^{S}$ is the set of varieties from country $j$ that gets exported to country $i .^{9}$

Trade is not balanced because of remittances. Let $R_{i}$ denote the net remittances received by country $i$, which can be positive (for countries receiving remittances), or negative (for countries sending them). ${ }^{10}$ Remittance-receiving countries will be able to afford imports above the value of their exports, while the opposite will be true for countries with negative net remittances.

9. It is understood that in the nontraded sector $\tau_{i j}^{N}=\infty \forall i \neq j$, and thus the summations are in effect over one nonzero element, $j=i$.

10. Of course, for the world as a whole, remittances sum to zero: $\sum_{i} R_{i}=0$. The data on remittances used in what follows to implement the model satisfy this requirement. 


\subsection{Short-Run and Long-Run Equilibria}

In assessing the welfare impact of migration, we consider two types of equilibria. The two equilibria differ in their assumptions on the mass of projects $n_{i}^{s}$ in each country and sector.

The short-run equilibrium assumes that the set of projects $n_{i}^{S}$ is fixed in each country and sector, as in Chaney (2008) and Eaton, Kortum, and Kramarz (2011), and thus it cannot adjust to changes in the labor force. A short-run monopolistically competitive equilibrium is a set of prices $\left\{w_{i}, P_{i}^{N}, P_{i}^{T}\right\}_{i=1}^{\mathcal{C}}$, and factor allocations such that (i) consumers maximize utility; (ii) firms maximize profits; and (iii) all goods and factor markets clear, given country endowments $L_{i}$ and $n_{i}^{s}$.

In the long-run equilibrium, the set of projects $n_{i}^{s}$ is an equilibrium outcome that responds to changing economic conditions, in our case migration. Each country has a potentially infinite number of entrepreneurs (projects) with zero outside option. In order to become an entrepreneur, an agent must pay an "exploration" cost $f_{E}$. Upon paying this cost, the entrepreneur $k$ discovers her productivity, indexed by a unit input requirement $a(k)$, and develops an ability to produce a unique variety of $N$ or $T$ valued by consumers and other firms. The equilibrium number of projects $n_{i}^{S}$ is then pinned down by the familiar free entry condition in each sector and each country, as in Krugman (1980) and Melitz (2003). A long-run monopolistically competitive equilibrium is a set of prices $\left\{w_{i}, P_{i}^{N}, P_{i}^{T}\right\}_{i=1}^{\mathcal{C}}$, equilibrium masses of projects $\left\{n_{i}^{N}, n_{i}^{T}\right\}_{i=1}^{\mathcal{C}}$, and factor allocations such that (i) consumers maximize utility; (ii) firms maximize profits; (iii) all goods and factor markets clear; and (iv) the net profits in the economy equal zero, given country endowments $L_{i} \forall i$.

Online Appendix A.1 presents the complete equations defining both types of equilibria.

\subsection{Mechanisms}

Immigration into country $i$ increases $L_{i}$. In addition to its impact on nominal wages, immigration will affect the natives' welfare by changing equilibrium product variety. The vectors of $n_{j}^{s}$ and the array of cutoffs (9) together determine the set of varieties offered in each country. ${ }^{11}$ An increase in the set of varieties available in country $i$ implies a lower price level and, other things equal, higher utility/real income. Consumers benefit directly from the variety-induced reduction in the price level, as well as indirectly through cheaper intermediate inputs available to firms.

However, in the presence of firm heterogeneity not all varieties are equally valuable: an unproductive variety (higher $a(k)$ ) raises welfare by less than a more productive one. Thus, changes in equilibrium variety due to movements in the $a_{i j}^{s}$ have a smaller welfare impact than those coming from changes in the $n_{j}^{s}$. This is because movements

11. For instance, the measure of domestic varieties available in sector $s$ in country $i$ is equal to $n_{i}^{s} G\left(a_{i i}^{s}\right)$. Of course, the total variety in the $T$ sector is the sum of domestic and imported varieties. 
in the $a_{i j}^{s}$ correspond to entry/exit of the least productive firms in the economy, whereas movements in the $n_{j}^{s}$ result in entry/exit along the entire firm size distribution.

In this respect, the critical difference between the long run and the short run is that in the long run, the $n_{j}^{s}$ will change in response to migration. In the short run, the set of projects $n_{j}^{s}$ is fixed. However, even in the short run the set of actual firms that serve the market - and thus the equilibrium product variety in the economy-will still change due to migration. This is because generically, not all projects are implemented in equilibrium, and migration changes the cutoffs $a_{i i}^{s} / a_{i j}^{s}$ for producing and exporting. Entry and exit do occur in the short run, but they are confined to the marginal firms, which are the least productive in the economy.

By contrast, in the long run entry/exit of firms will occur along the entire productivity distribution, rather than only among the least productive firms. A wellknown property of monopolistic competition models with free entry is that $n_{i}^{s}$ increases in $L_{i}$ : larger countries have a greater set of projects. ${ }^{12}$ Migration thus affects welfare in the long run by changing $n_{i}^{s}$. Natives in countries that end up with larger $L_{i}$ because of immigration will be better off, all else equal, because immigration will lead to greater equilibrium variety (see the expressions for the price indices (10)).

International trade will mitigate this effect because changes in the availability of foreign varieties also have a welfare impact. For instance, suppose that country $i$ loses workers to country $j$. As a result, product variety will fall in $i$ and rise in $j .{ }^{13}$ From equation (10), it is clear that an increase in foreign $n_{j}^{T}$ will also have a positive impact on welfare in country $i$ due to an increase in the set of varieties imported from $j$. However, due to trade costs increases in foreign $n_{j}^{T}$ are less valuable for country $i$ than increases in its own $n_{i}^{T}$ and $n_{i}^{N}$. Thus, while greater imported variety will counteract the impact of migration on domestically available variety, it will not do so fully, and the size of this mitigation effect is ultimately a quantitative question. We answer it in what follows by calibrating the size of the nontraded sector and the trade costs in the traded sector, and by comparing the main results to an alternative counterfactual exercise in which the trade channel is turned off.

By contrast, input-output linkages embodied in the cost function (7) will raise the welfare impact of changes in domestically available varieties, and will thus amplify the welfare impact of migration. The magnitude of this effect is a quantitative question, and thus we calibrate the parameters $\beta_{s}$ and $\eta_{s}$ that regulate the strength of input-output linkages based on observed Input-Output tables.

Finally, though capital is not explicitly in the model, one can follow the interpretation suggested by Ghironi and Melitz (2005) and Bergin and Corsetti (2008) that the set of projects available to entrepreneurs is a form of the capital endowment.

12. While the full-fledged, multisector model with unbalanced trade in this paper cannot be used to show this relationship analytically, di Giovanni and Levchenko $(2012,2013)$ show the positive relationship between $L_{i}$ and $n_{i}^{s}$ in somewhat simpler models with symmetric countries.

13. The exact change in variety in each country will depend on the labor productivity parameters $A_{i i}$ and $A_{j j}$. If we assume that the origin country has lower labor productivity than the destination-as is typically the case - then there may be a net increase in worldwide product variety. 
TABLE 3. Calibrated parameter values.

\begin{tabular}{lcl}
\hline Parameter & Baseline & \multicolumn{1}{c}{ Source } \\
\hline$\sigma$ & 3 & Ottaviano and Peri (2012) \\
$\varepsilon^{s}$ & 6 & Anderson and van Wincoop (2004) \\
$\theta^{s}$ & 5.3 & Axtell (2001): $\theta /(\varepsilon-1)=1.06$ \\
$\alpha$ & 0.65 & Uy, Yi, and Zhang (2013) \\
$\left\{\beta_{N}, \beta_{T}\right\}$ & $\{0.65,0.35\}$ & 1997 US Benchmark Input-Output Table \\
$\left\{\eta_{N}, \eta_{T}\right\}$ & $\{0.77,0.35\}$ & \\
$\tau_{i j}$ & 2.30 & Helpman, Melitz, and Rubinstein (2008) \\
$f_{i i}^{S}$ & 14.24 & The World Bank (2007); normalizing $f_{U S, U S}$ \\
$f_{i j}$ & 7.20 & so that nearly all firms the US produce \\
$f_{E}$ & 34.0 & To match 7,000,000 firms in the United States \\
& & (US Economic Census) \\
\hline
\end{tabular}

Notes: The details of how these parameters are chosen are described in Online Appendix A.2.

Similarly, the creation of new firms is a form of capital investment. This interpretation is natural in the sense that these projects are in effect a factor of production without which workers cannot generate output. Thus, the short-run equilibrium corresponds to a case in which the other factors of production $-n_{j}^{s}$ here- have not had a chance to adjust to the new endowment of labor, whereas the long-run equilibrium is the one that obtains after the adjustment of other factors.

\section{Quantitative Implementation and Model Fit}

We numerically implement the model laid out in Section 3. We use information on country sizes, fixed and variable trade costs, and bilateral migration flows and remittances to solve the model in the baseline scenario- that is, under the observed levels of migration and remittances. Then in Section 5 we simulate the effects of undoing the migration flows observed in the data. That is, we repatriate all immigrants in the OECD countries back to their countries of origin. Table 3 summarizes the calibrated parameter values of the model, and Online Appendix A.2 discusses the details of how the parameters are chosen.

\subsection{Labor Productivity Parameters}

To complete the implementation of the baseline scenario requires finding the values of $L_{j}$, or equivalently, $A_{j j}$. While we have actual data on the numbers of natives and immigrants $N_{j i}^{e}$ in each origin and destination, $L_{j}$ is not population per se, but a combination of the number of workers and the efficiency units - or labor productivitypossessed by workers in country $j$ (Section 3.2).

To find $L_{j}$ we follow the approach of Alvarez and Lucas (2007). Starting with an initial guess for $L_{j}$ for all $j=1, \ldots, \mathcal{C}$, we solve the full model in the long-run 
equilibrium. Given the solution for $w_{j}$, we update our guess for $L_{j}$ for each country in order to match the nominal US\$ GDP ratio between each country $j$ and the United States. Using the resulting values of $L_{j}$, we solve the model again to obtain the new set of wages, and iterate to convergence. Thus, our procedure generates vectors $w_{j}$ and $L_{j}$ in such a way as to match exactly the relative total GDPs of the countries in the sample while imposing that the model world economy is in the long-run equilibrium.

Having obtained the total efficiency-adjusted labor endowments $L_{j}$, and using the data on bilateral immigrant stocks by skill for each destination and origin country, we obtain country-specific productivity $A_{j j}$ for every country $j$ from equation (6):

$$
A_{j j}=\frac{L_{j}}{\left[\left(\sum_{i=1}^{\mathcal{C}} \varphi_{j i}^{\ell} N_{j i}^{\ell}\right)^{\frac{\sigma-1}{\sigma}}+\zeta_{j}\left(\mu_{j} \sum_{i=1}^{\mathcal{C}} \varphi_{j i}^{h} N_{j i}^{h}\right)^{\frac{\sigma-1}{\sigma}}\right]^{\frac{\sigma}{\sigma-1}}} .
$$

Intuitively, this procedure infers productivity from total country GDPs and the labor force composition of each country. Section 4.2 checks that the resulting productivity estimates are plausible. A notable consequence of this approach is that, controlling for population, countries with higher labor productivity $A_{j j}$ will tend to have a greater number of entrepreneurs $n_{j}^{s}$, all else equal, since our procedure will give them a higher $L_{j} \cdot{ }^{14}$

The previous calculation requires assigning values to (i) the term $\zeta_{j} \mu_{j}^{\sigma-1 / \sigma}$, and (ii) $\varphi_{j i}^{e}$. We calibrate $\zeta_{j} \mu_{j}^{\sigma-1 / \sigma}$ using skill premia. Optimal factor usage implies the following relationship:

$$
\frac{w_{j}^{h}}{w_{j}^{\ell}}=\zeta_{j} \mu_{j}^{\frac{\sigma-1}{\sigma}}\left(\frac{\sum_{i=1}^{\mathcal{C}} \varphi_{j i}^{h} N_{j i}^{h}}{\sum_{i=1}^{\mathcal{C}} \varphi_{j i}^{\ell} N_{j i}^{\ell}}\right)^{-\frac{1}{\sigma}},
$$

where $w_{j}^{e}$ is the wage of the worker of skill level $e=\ell, h$. Using countryspecific data on the skill premium $w_{j}^{h} / w_{j}^{\ell}$ described in Section 2 as well as the population composition by skill $\sum_{i=1}^{\mathcal{C}} \varphi_{j i}^{h} N_{j i}^{h}$ and $\sum_{i=1}^{\mathcal{C}} \varphi_{j i}^{\ell} N_{j i}^{\ell}$ allows us to back out the combination $\zeta_{j} \mu_{j}^{\sigma-1 / \sigma}$ of the skill share parameter and the skilled worker's productivity advantage. This procedure ensures that the baseline equilibrium matches perfectly the observed skill premium in each country.

On $\varphi_{j i}^{e}$, we adopt three approaches. The first is to assume that $\varphi_{j i}^{\ell}=\varphi_{j i}^{h}=1$, common across all countries. In this case, the average equilibrium wages of natives and immigrants with the same skill level will be equal within each country (although they will of course differ across countries). This will be our baseline scenario as we find it helpful in conveying the main mechanisms driving our results. It corresponds

14. That is, population and efficiency enter symmetrically and multiplicatively in determining market size, which in turn determines equilibrium variety. This approach is common in the literature. For instance, Alvarez and Lucas (2007) and Chaney (2008) assume that the number of productivity draws is a constant multiple of $L_{j}$. 
TABLE 4. Bilateral trade shares: data and model predictions.

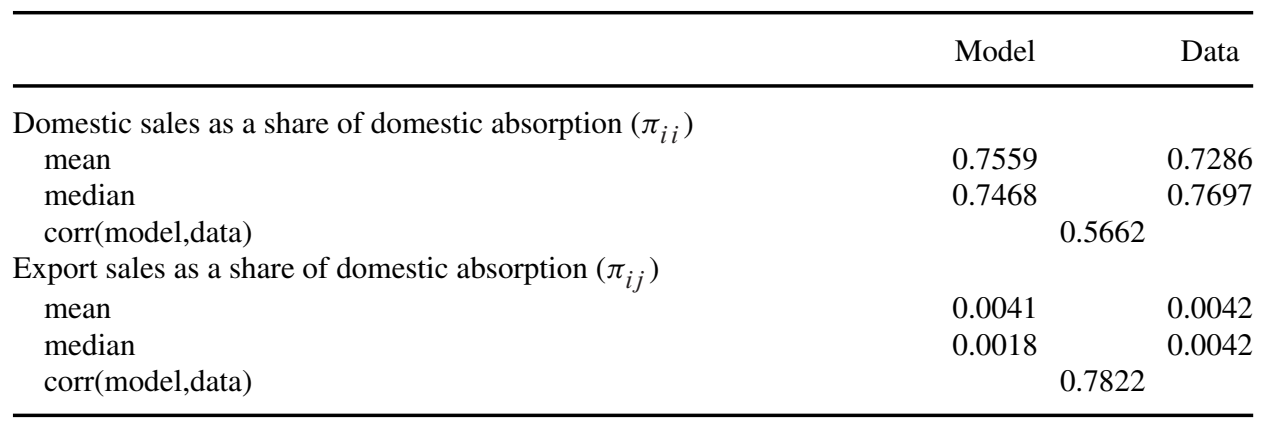

Notes: This table reports the means and medians of domestic output (top panel), and bilateral trade (bottom panel), both as a share of domestic absorption, in the model and in the data.

Source: International Monetary Fund (2007) and model output.

to the broad pattern in the data that the wages of migrants are well approximated by the wages of the natives in the host country, and are often an order of magnitude larger than wages of similar workers in the source country (Pritchett 2006).

We check the robustness of the results to two alternative calibrations of $\left\{\varphi_{j i}^{e}\right\}$. The first captures a plausible amount of imperfect cross-border transferability of skills. The second allows for origin-specific native-immigrant productivity gaps that reflect migrant selection (positive or negative), or differences in the quality of education across countries. The results and a more detailed discussion are in Section 6 and Online Appendix B.1.

\subsection{Model Fit}

Before describing the counterfactual results, we assess the model fit on overall and bilateral trade, as well as on how the total labor productivities implied by the model compare to GDP per capita at the country level. The baseline is solved as the long-run equilibrium given the population compositions, total GDPs, and remittances in all countries as they are in the data in 2006.

Table 4 compares the bilateral and overall trade volumes in the model and in the data. Note that since in the data we only have bilateral trade as a share of GDP, not of total sales, we compute the same object in the model: $\pi_{i j}=X_{i j} / w_{i} L_{i} \cdot{ }^{15}$ This captures both the distinction between trade, which is recorded as total value, and GDP, which is recorded as value added-as well as the fact that there is a large nontraded sector in both the model and in the data.

The top panel of the table compares the share of domestically produced goods in GDP, $\pi_{i i}$, which is one minus imports/GDP, and can be thought of as the opposite of trade openness. It is clear that the overall trade volumes implied by the model match the actual data well. The means and medians are similar, and the correlation between

15. Since the baseline is solved as the long-run equilibrium, total profits are zero and GDP is simply labor income. 
$\pi_{i i}$ calculated from the model and those in the data for this sample of countries is around 0.57 . The bottom panel compares bilateral trade shares $\pi_{i j}, i \neq j$. The average levels are quite similar, and the correlation between model and data bilateral trade shares is actually higher at 0.78 . Since we use estimated gravity coefficients together with the actual data on bilateral country characteristics to compute trade costs, it is not surprising that our model fits bilateral trade data quite well given the success of the empirical gravity relationship. Nonetheless, since the gravity estimates we use come from outside of our calibration procedure, it is important to check that our model delivers outcomes similar to observed trade volumes.

The model delivers a vector of implied baseline labor productivities $A_{j j}$ for each country, and we would like to compare these estimates to the data. Unfortunately, as a model object $A_{j j}$ reflects the physical productivity of a worker, which we cannot measure in the data. In addition, in the model wages of a single efficiency unit of labor, $w_{j}$, will differ across countries to ensure global market clearing. To match the model precisely with the data, we calculate in the model the real PPP-adjusted per capita income for an individual living in $j$, which is given by

$$
\frac{w_{j} L_{j}}{P_{j} \sum_{i} \sum_{e=\ell, h} N_{j i}^{e}},
$$

with $P_{j}=\left(P_{j}^{N}\right)^{\alpha}\left(P_{j}^{T}\right)^{1-\alpha}$ the consumption price level, and $\sum_{i} \sum_{e=\ell, h} N_{j i}^{e}$ simply the total population of country $j$. This object is then directly comparable to income data from the Penn World Tables. Figure 1 presents the scatterplot of the real PPPadjusted per capita income for 2006 from the Penn World Tables on the $x$-axis against the corresponding object in the model, along with the 45-degree line. The model matches the broad variation in per capita income in our sample of countries quite well. The countries line up along the 45-degree line, though it appears that the model tends to underpredict the relative income levels of poorer countries, and slightly overpredict the relative income levels of the richest countries. Overall, however, both the simple correlation and the Spearman rank correlation between the model and the data are $0.94 .^{16}$

\section{Counterfactuals}

Our counterfactual experiments evaluate the welfare effects of sending all foreign-born individuals currently living in the OECD countries back to their countries of birth. In

16. The plots and the correlations are reported dropping the United Arab Emirates (UAE), for which the model underpredicts real per capita income by about a factor of 2 . The UAE is a very small, special economy for which we do not have immigration data, and thus the poor performance of the model regarding the UAE is highly unlikely to affect any of the substantive results in the paper. Including the UAE, the simple correlation between the model and the data is 0.91 , and the Spearman correlation is still 0.94. 


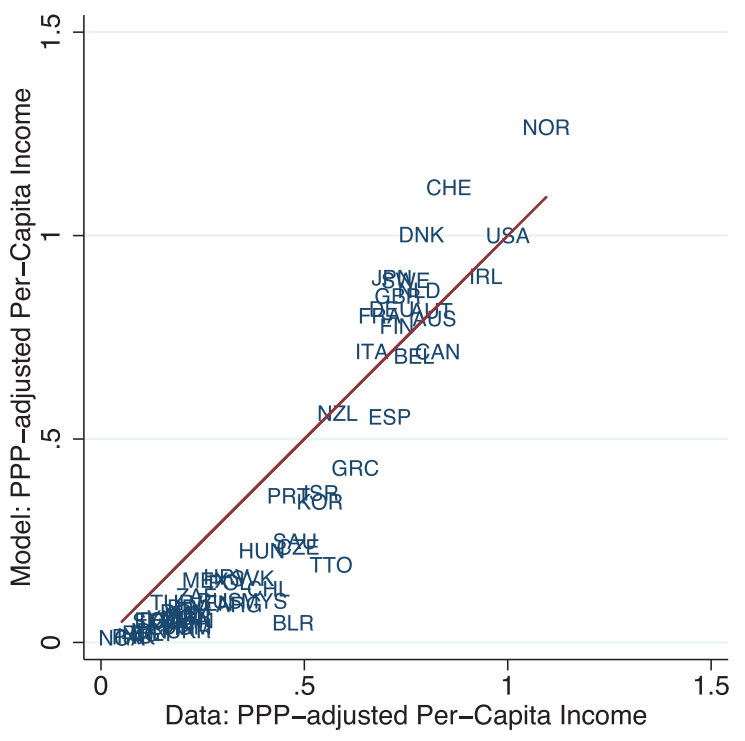

FIGURE 1. Real incomes: model versus data. This figure reports the scatterplot of the real PPPadjusted per capita income from the Penn World Tables ( $x$-axis) against the real PPP-adjusted per capita income implied by the model. Both are expressed relative to the United States.

the counterfactual scenario effective labor endowments of each country $j$ will be

$$
\widetilde{L}_{j}=A_{j j}\left[\left(\sum_{i=1}^{\mathcal{C}} N_{i j}^{\ell}\right)^{\frac{\sigma-1}{\sigma}}+\zeta_{j}\left(\mu_{j} \sum_{i=1}^{\mathcal{C}} N_{i j}^{h}\right)^{\frac{\sigma-1}{\sigma}}\right]^{\frac{\sigma}{\sigma-1}}
$$

That is, all the workers native to $j$ that ever migrated to any destination country $i$ are returned home. Their labor productivity is assumed to be the same as for their compatriots with the same skill, regardless of whether and where they migrated. ${ }^{17}$

Our main measure of welfare is the average utility of native stayers, taking into account the distribution of skill levels among them. ${ }^{18}$ Individual welfare is given by equation (1). In the baseline equilibrium the welfare of the native stayers (born and residing in $j$ ) is given by

$$
W_{j j}=\frac{\left(1-\omega_{j j}\right) w_{j}^{\ell}+\omega_{j j} w_{j}^{h}+\left(\Pi_{j}^{N}+\Pi_{j}^{T}\right) / \sum_{e=\ell, h} \sum_{k=1}^{\mathcal{C}} N_{j k}^{e}+R_{j}^{i n} / N_{j j}}{\left(P_{j}^{N}\right)^{\alpha}\left(P_{j}^{T}\right)^{1-\alpha}}
$$

17. In reality, return migrants may bring back skills learned at the destination country. However, there are very few estimates available for the rates of return to those skills. For more details see Dustmann (2003, 2008) and Dustmann, Fadlon, and Weiss (2011). See also Rauch and Trindade $(2002,2003)$ for estimates of the effects of migration on enhancing trade flows via the information conveyed through ethnic networks.

18. Online Appendix B.6 reports estimates of the welfare changes for the migrants themselves. 
where, as previously, $w_{j}^{e}$ is the wage of a native-born individual of skill level $e$, $\omega_{j j} \equiv N_{j j}^{h} /\left(N_{j j}^{\ell}+N_{j j}^{h}\right)$ is the share of skilled among the natives, $N_{j j}=N_{j j}^{\ell}+N_{j j}^{h}$ is the total population of natives, $\sum_{e=\ell, h} \sum_{k=1}^{\mathcal{C}} N_{j k}^{e}$ is the total population of country $j$, and $R_{j}^{i n}$ is the total gross amount of remittances received by country j. ${ }^{19}$

This expression for welfare thus makes an assumption on remittances and an assumption on the distribution of firm profits. On remittances, we assume that (i) outgoing remittances are sent by the migrants only, that is, natives living in their home country are not transferring any of their income abroad; and that (ii) incoming remittances are received by the native stayers only, that is, remittances from abroad coming into the country go to natives, and not to immigrants living in that country. ${ }^{20}$ On profits, we assume that all residents of a country have an equal number of shares in domestic profits, regardless of their skill level or country of birth. ${ }^{21}$ This is a strong assumption, but it only matters in the short run. In the long run, profits are zero due to free entry.

In the counterfactual scenario each country's population is composed of the individuals that were born in that country, including both those that never left and returnees. The expressions for individual welfare in the counterfactual equilibrium are analogous to the previous expressions, with the proviso that there are no longer any remittances. Hence, the counterfactual individual welfare of a native stayer in country $j$ is given by

$$
\widetilde{W}_{j j}=\frac{\left(1-\omega_{j j}\right) \tilde{w}_{j}^{\ell}+\omega_{j j} \tilde{w}_{j}^{h}+\left(\tilde{\Pi}_{j}^{N}+\tilde{\Pi}_{j}^{T}\right) / \sum_{k=1}^{\mathcal{C}} N_{k j}}{\left(\tilde{P}_{j}^{N}\right)^{\alpha}\left(\tilde{P}_{j}^{T}\right)^{1-\alpha}},
$$

where the tilde denotes the counterfactual equilibrium values.

The change in the average welfare of natives between the baseline and the nomigration scenarios is closely related to the concept of the immigration surplus, defined as the change in the real average income of natives caused by an inflow

19. Recall that $R_{j}$ was used to denote the total net remittances received by country $j$ from the rest of the world, which can take both positive and negative values.

20. For example, remittances from Mexicans working in the United States are received by native Mexicans living in Mexico, and not by Guatemalan immigrants living in Mexico or by Mexicans living in Spain. We lack data to evaluate the plausibility of this assumption but it appears reasonable and unlikely to bias the results.

21. We are not aware of a good empirical benchmark that directly speaks to the question of the immigrants' share of a country's total profits. However, it is helpful to compare the entrepreneurship rates of natives and immigrants. Fairlie (2012) reports a higher business ownership rate among immigrants $(10.5 \%)$ than among natives $(9.3 \%)$ in the United States. Likewise the startup rate is also higher for immigrants than for non-immigrants $(0.62 \%$ versus $0.28 \%)$. However, these figures are likely to overestimate the share of profits accruing to immigrants because immigrant-owned businesses tend to be smaller than native-owned ones. According to Fairlie (2012) immigrant-owned businesses have about 30\% lower revenue. In light of these numbers it appears reasonable to allocate aggregate profits to natives and immigrants in proportion to their population shares. 
of immigrants (Berry and Soligo 1969; Borjas 1995). Virtually all studies that quantify the immigration surplus employ a one-good framework and a standard neoclassical production function. In our framework each firm produces a different good and product variety is endogenous. In this context income is deflated by the ideal price index, which encapsulates the impact of changes in product variety on firms and consumers. But it is still the case that real income per native, our main welfare criterion, coincides with the immigration surplus also in per-native terms.

\subsection{The Long Run}

Table 5 reports our main results. For each country, we report the percent change in the real average income of native stayers (across the two skill levels) in the no-migration counterfactual relative to the benchmark scenario. Negative values thus represent welfare losses from undoing international migration. We break up the sample into the OECD and the non-OECD countries. Roughly, we can think of the OECD group (left panel) as the migrant-receiving countries and the non-OECD group (right panel) as the migrant-sending countries, though keeping in mind that there is substantial migration within the OECD as well.

The first important observation is that in the long run the large majority of OECD countries would be worse off in the absence of migration. The average OECD country would experience a welfare change of $-2.38 \%$, with substantial dispersion in outcomes (standard deviation of 3.07\%). In this group, the largest losses are experienced by the natives of the countries with the largest observed shares of the foreign-born in the population: Australia $(-11.63 \%)$, Canada $(-7.07 \%)$, and New Zealand $(-6.89 \%)$. However, it is worth noting that a handful of OECD countries would experience welfare gains: Greece, Korea, and Portugal would all be about $1.1 \%-1.4 \%$ better off in the no-migration counterfactual. As Table 1 shows, these are the OECD countries with noticeable net out-migration. In the no-migration counterfactual these countries' population would rise by $5.2 \%, 2.8 \%$, and $11.1 \%$, respectively.

Second, the majority of non-OECD countries also have lower welfare in the no-migration counterfactual, although dispersion in country outcomes is substantial. The average welfare change is $-2.00 \%$ with an associated standard deviation of $3.55 \%$. The highest welfare losses are to native stayers in El Salvador, the Dominican Republic, Jamaica, and the Philippines, at around $-7 \%$ to $-10 \%$. Interestingly, a handful of non-OECD countries experience welfare gains: mainly, Trinidad and Tobago $(5.70 \%)$, Mexico (1.32\%), and Turkey (1.07\%). A quick glance at Table 2 shows that these countries are characterized by substantial emigration rates but small incoming remittances relative to their GDP and to their emigration rates. For instance, while Mexico has an emigration rate over $10 \%$, remittances amount to only $3.1 \%$ of its GDP. In contrast, the emigration rate of the Philippines is around 3\% but the incoming remittances are equal to $15.5 \%$ of its GDP. ${ }^{22}$

22. However, it is also important to qualify the impact of cross-country variation in incoming remittances. In our framework remittances are exogenous and taken directly from the data. As such, our analysis is 
TABLE 5. Percentage change in average welfare in the counterfactual relative to benchmark.

\begin{tabular}{|c|c|c|c|c|c|}
\hline \multirow[b]{2}{*}{ Country } & \multicolumn{2}{|c|}{ OECD countries } & \multirow[b]{2}{*}{ Country } & \multicolumn{2}{|c|}{ Non-OECD countries } \\
\hline & Long run & Short run & & Long run & Short run \\
\hline Australia & -11.63 & -0.68 & Algeria & -1.55 & -2.14 \\
\hline Austria & -3.06 & -0.41 & Argentina & 0.07 & -0.19 \\
\hline Belgium & -4.63 & -1.36 & Belarus & -1.25 & -1.03 \\
\hline Canada & -7.07 & 0.25 & Brazil & -0.27 & -0.43 \\
\hline Czech Republic & -1.02 & -0.85 & Bulgaria & -5.68 & -6.60 \\
\hline Denmark & -1.29 & -0.31 & Chile & 0.34 & -0.11 \\
\hline Finland & -0.13 & -0.55 & China & -0.75 & -0.88 \\
\hline France & -3.12 & -0.39 & Colombia & -2.01 & -2.75 \\
\hline Germany & -1.55 & -0.09 & Croatia & -0.35 & -3.29 \\
\hline Greece & 1.17 & -0.59 & Dominican Republic & -9.02 & -11.55 \\
\hline Hungary & -0.46 & -0.12 & Ecuador & -2.26 & -4.42 \\
\hline Ireland & -0.07 & -0.54 & Egypt, Arab Rep. & -3.47 & -3.40 \\
\hline Italy & 0.43 & -0.15 & El Salvador & -8.72 & -14.08 \\
\hline Japan & -0.48 & -0.01 & India & -2.51 & -2.53 \\
\hline Korea, Rep. & 1.12 & -0.01 & Indonesia & -0.65 & -0.63 \\
\hline Netherlands & -2.60 & -0.12 & Iran, Islamic Rep. & -0.15 & -0.53 \\
\hline New Zealand & -6.89 & -1.21 & Israel & 0.12 & -0.04 \\
\hline Norway & -2.53 & -0.05 & Jamaica & -5.61 & -14.89 \\
\hline Poland & 0.16 & -1.32 & Malaysia & -0.39 & -0.43 \\
\hline Portugal & 1.37 & -2.04 & Mexico & 1.32 & -2.59 \\
\hline Slovak Republic & -0.10 & -1.10 & Nigeria & -2.74 & -2.59 \\
\hline Spain & -4.91 & -0.42 & Pakistan & -3.45 & -3.45 \\
\hline Sweden & -3.45 & 0.15 & Philippines & -10.08 & -11.27 \\
\hline Switzerland & -4.42 & 0.06 & Romania & -2.73 & 4.89 \\
\hline United Kingdom & -1.46 & -0.23 & Russian Federation & -0.18 & -0.38 \\
\hline \multirow[t]{9}{*}{ United States } & -5.37 & 0.14 & Saudi Arabia & -0.26 & 0.66 \\
\hline & & & Serbia and Montenegro & -11.54 & -14.46 \\
\hline & & & South Africa & -0.05 & -0.31 \\
\hline & & & Thailand & -0.51 & -0.56 \\
\hline & & & Trinidad and Tobago & 5.70 & -0.77 \\
\hline & & & Turkey & 1.07 & -0.30 \\
\hline & & & Ukraine & -0.34 & --0.58 \\
\hline & & & United Arab Emirates & -0.06 & -0.07 \\
\hline & & & Venezuela, RB & 0.10 & -0.14 \\
\hline Mean & -2.38 & -0.46 & Mean & -2.00 & -3.28 \\
\hline Std Dev. & 3.07 & 0.56 & Std Dev. & 3.55 & 4.54 \\
\hline
\end{tabular}

Notes: This table presents the percent change in welfare between baseline and counterfactual equilibria, assuming $\varphi_{i}^{\ell}=\varphi_{i}^{h}=1$ for all countries. The measure of welfare employed here is the average real income of native stayers. The first column reports the welfare change in the long run, the second column in the short run.

silent on why remittances, conditional on emigrant stocks, vary across countries. It could be that in some countries entire families emigrate, while in others families are split and only one family member goes abroad. These patterns have clear implications for remittance flows (Merkle and Zimmermann 1992), but will also presumably have a direct and unmodeled impact on the disutility from emigration if people value living in the same location as their family. 


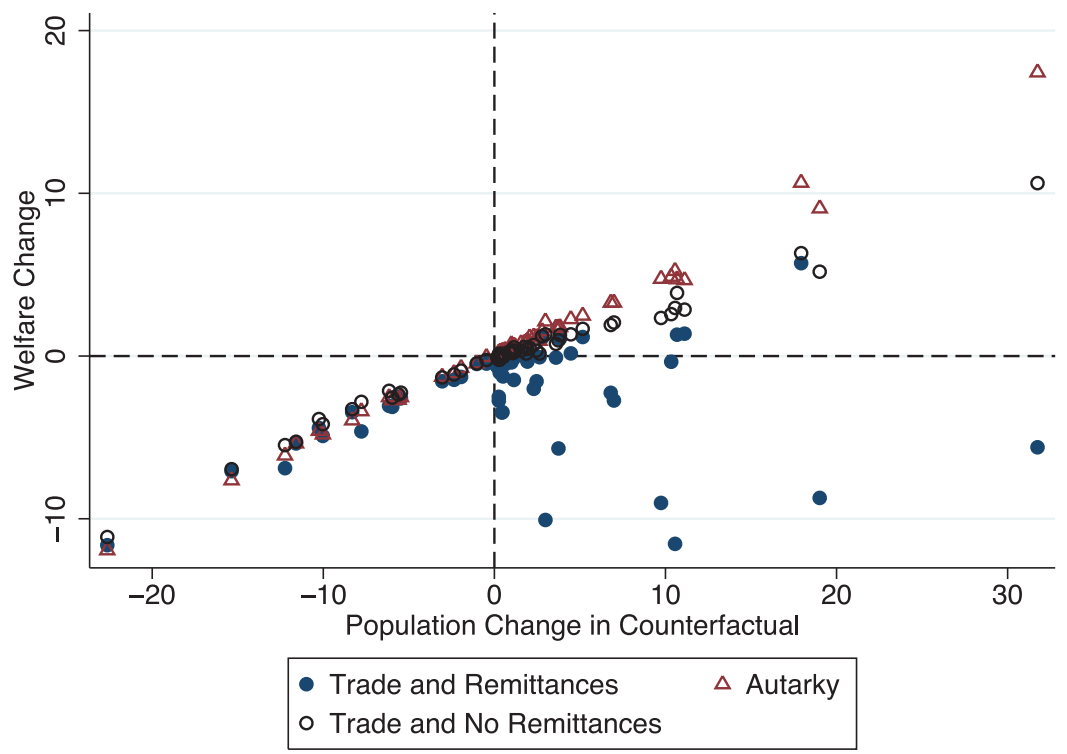

FIGURE 2. Change in average welfare in the long run: autarky, trade, and remittances. This figure reports the percentage change in welfare in the long-run counterfactual relative to the baseline (assuming $\varphi_{i}^{\ell}=\varphi_{i}^{h}=1$ for all countries $i$ ) in three different scenarios. Solid dots depict the welfare change with both trade and remittances. Hollow dots depict the welfare change with international trade but keeping remittances constant at zero in the baseline and counterfactual equilibria. Hollow triangles depict the welfare changes under prohibitive trade costs and no remittances. The measure of welfare is the average real income of native stayers. On the $y$-axis is the percent change in the population in the counterfactual relative to the baseline.

Thus, both developed and developing countries tend to gain from the observed levels of migration. In the OECD, net immigration leads to a larger market size. In the presence of positive trade costs, this implies higher equilibrium variety and thus higher per capita welfare. For the native stayers in the non-OECD, the losses from lower variety due to emigration are in most cases more than offset by the fact that their emigrants experience large increases in earnings, and a fraction of those is being shared with the native stayers through remittances.

We now isolate the roles played by changes in population size, international trade, and remittances. Figure 2 presents these results using scatterplots. On the horizontal axis is the percentage change in the total population in the counterfactual relative to the baseline (column 3 of Table 1 and column 1 of Table 2), with positive values corresponding to increases in population. On the vertical axis is the percentage change in welfare in the no-migration counterfactual relative to the baseline. Solid dots depict the long-run welfare change (the first column of Table 5). As discussed previously, most countries in the OECD suffer a population loss as migrants return to their home countries, while most non-OECD countries gain population. Among the OECD countries there is a clear positive association between the population change and the percentage change in long-run welfare: the countries with the largest population 
losses suffer the largest welfare losses. For instance, Australia would lose $22.6 \%$ of its population, leading to a $-11.63 \%$ welfare change for its native stayers. The picture is much less clear for the non-OECD countries. Most of these countries experience net population gains. However, some suffer large welfare losses while others even experience (small) welfare gains. It is particularly interesting to compare the predictions for El Salvador and Trinidad and Tobago. These two countries would experience similar population gains due to return migration, at $19 \%$ and $17.9 \%$ respectively. But while the former would suffer a welfare loss of $-8.72 \%$, the latter would experience a welfare gain of $5.70 \%$. As we now show, the diverging effects of return migration on these two countries are explained by the role of remittances.

Figure 2 plots the results from two additional counterfactual scenarios. Hollow dots report the welfare changes that would result assuming there are no remittances. Strikingly, the relationship between population and welfare changes becomes roughly monotonically increasing, with a concave shape. In particular, we note that El Salvador and Trinidad and Tobago would now experience practically the same welfare gain (about 5\%). The key is that remittances are a very large share of income in El Salvador, but not in Trinidad and Tobago. Note also that for the OECD the welfare impact remains practically unchanged. This is because the remittances originating in these countries are very small relative to the countries' GDPs, and the native stayers are not the ones sending them abroad.

Next, we examine the scenario where both remittances and international trade are assumed away. The corresponding welfare changes are depicted by hollow triangles. The relationship between population and welfare changes becomes practically linear (with a slope of 0.5), and steeper than under trade. This is because when a developing country experiences net population growth it will respond by producing a wider set of varieties. In autarky, consumers in that country clearly benefit from the increase in variety. However, in the presence of trade the resulting welfare gain is moderated by the reduction in the number of varieties that are available through imports, implying a smaller marginal welfare gain.

\subsection{The Short Run}

The native stayers' welfare changes in the short run are reported in the second column of Table 5. Welfare for natives in the OECD is practically unchanged in the short run (an average change of $-0.46 \%$, compared to $-2.38 \%$ in the long run). In the non-OECD, all countries would experience a welfare loss (with the exception of Saudi Arabia). Furthermore, the short-run loss is uniformly larger than the long-run loss $(-3.28 \%$, compared to $-2.00 \%$ in the long run). The intuition for the difference between the short- and long-run effects is as follows. The typical OECD country experiences a net reduction in its labor force. As a result, some of the firms operating in the OECD shut down. In the short run, the set of projects available in the economy is fixed. Hence, the reduction in the number of firms/varieties is attained by an increase in the productivity cutoff for operating a firm. As a result, the firms that exit are those with the lowest productivity. Losing these marginal varieties has practically no effect on the welfare 
of natives in the OECD. At the other end, developing countries receive a net inflow of workers. This increase in the labor force will induce a reduction in the productivity cutoff for operating a firm there, and new firms will be established. However, these are firms that did not find it worthwhile to operate before the inflow of new workers. Thus, their positive contribution to welfare-adjusted equilibrium variety is minor.

Quantitatively, in the short run, what matters crucially is how much less productive new entrants are relative to the firms that are already in the market. For this, the calibration to the observed firm size distribution (Zipf's Law) plays an important role. Essentially, the observed firm size distribution contains information on the relative productivity of the marginal firms compared to the inframarginal ones. The extremely skewed firm size distribution observed in the economy implies that the inframarginal firms are vastly more productive, and thus matter much more for welfare, than the marginal ones (for a detailed exploration of this result, see di Giovanni and Levchenko 2013). In comparison, the main benefit in the long run from having a larger population lies in the additional net entry of entrepreneurs-a larger $n_{i}^{s}$. An increase in population stimulates entry everywhere in the productivity distribution. Because the long-run entry will feature some very productive firms, it will have a much larger impact on welfare.

Three OECD countries-Sweden, Switzerland, and the United States-gain in welfare from undoing migration in the short run. It turns out that this outcome is due to the assumption that immigrants receive a per capita share of firm profits. If we instead assume that all the firm profits in the economy accrue to the natives, even in these three countries the natives are worse off without immigration.

Figure 3 reports the short-run results graphically and isolates the roles of remittances and international trade. As was the case in the long run, not taking into account remittances, the relationship between population and welfare changes becomes roughly monotonic. As illustrated by the hollow dots, with trade but no remittances, larger population gains in the counterfactual lead to larger welfare losses among developing countries. In the OECD the relationship appears practically flat. In other words, in the short run the increase in domestic varieties experienced by developing countries is not enough to compensate for the loss in imported varieties. The main reason for this is that return migrants are leaving high-productivity OECD countries to go back to their low-productivity countries of origin, which entails a large loss in worldwide efficiency units of labor. Turning now to the role of international trade, in the counterfactual exercise without either remittances or cross-border trade, the relationship between population and welfare changes again becomes roughly linear and now features a weak positive slope. This reflects the fact that the increased labor force in the non-OECD will deliver a net increase in varieties available for consumption, obviously with no change in imported varieties.

\subsection{Distributional Effects}

Our model features imperfect substitutability between skilled and unskilled workers, and thus the potential for migration to generate distributional effects to the extent that 


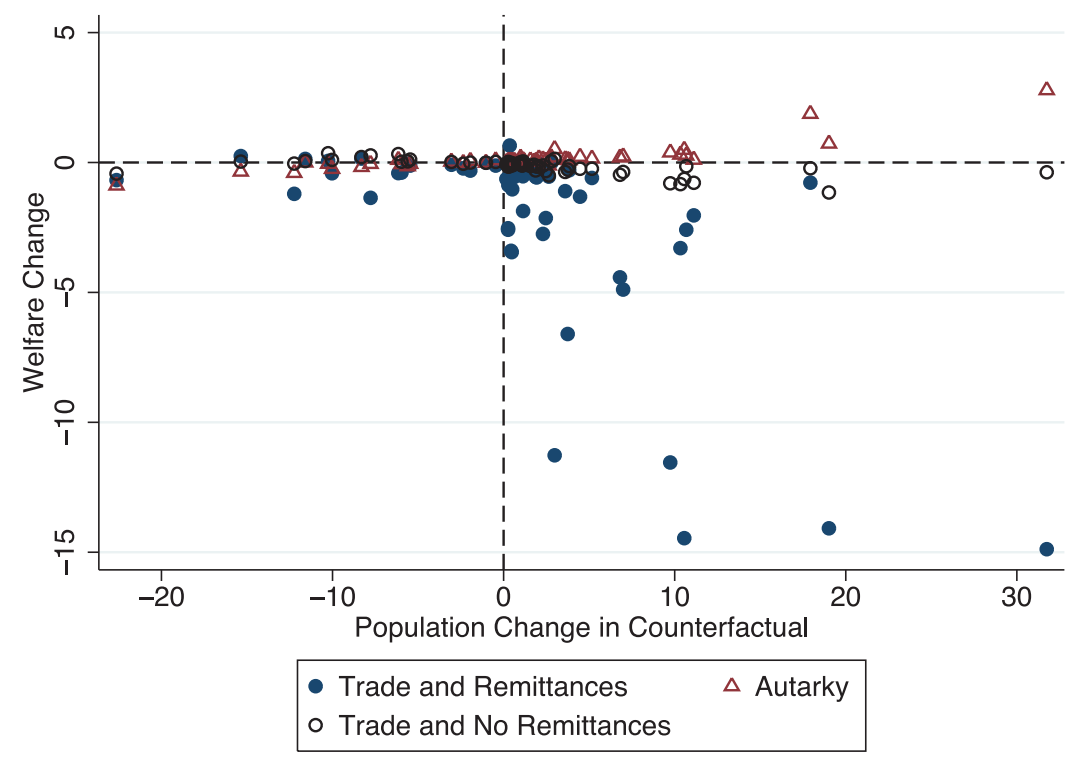

FIGURE 3. Change in average welfare in the short run: autarky, trade, and remittances. This figure reports the percentage change in welfare in the short-run counterfactual relative to the baseline (assuming $\varphi_{i}^{\ell}=\varphi_{i}^{h}=1$ for all countries $i$ ) in three different scenarios. Solid dots depict the welfare change with both trade and remittances. Hollow dots depict the welfare change with international trade but keeping remittances constant at zero in the baseline and counterfactual equilibria. Hollow triangles depict the welfare changes under prohibitive trade costs and no remittances. The measure of welfare is the average real income of the native stayers. On the $y$-axis is the percent change in the population in the counterfactual relative to the baseline.

migrants differ in skill composition from natives. To isolate those distributional effects, Figure 4 plots the welfare changes of the unskilled native stayers against the welfare changes of the skilled native stayers. If a country observation is on the 45-degree line, the skilled and the unskilled experience identical welfare changes.

The top panel presents the results for the OECD. Overall, welfare changes for the skilled and the unskilled are similar: the observations tend to be relatively close to the 45-degree line (Figure 4a). Thus, in the long run the welfare gains from new varieties dominate the changes in the skill premium. A notable exception is Australia: the unskilled stayers lose $13.6 \%$ in the no-migration counterfactual, compared to $7.8 \%$ for the skilled. This reflects the fact that immigrants to Australia are more skilled on average than natives (Table 1).

However, in the short run the distributional effects come to the fore (Figure 4b). In many OECD countries, the welfare changes for the skilled and the unskilled have opposite signs, and are an order of magnitude larger in absolute value than aggregate welfare changes. For instance, in the short run the United States is $0.14 \%$ better off without migration (Table 5). Separating by skill, it turns out that the unskilled are $1.03 \%$ better off in the absence of migration, but the skilled are $0.45 \%$ worse off. In Australia, the numbers are even larger, and the identity of winners and losers is reversed. While 


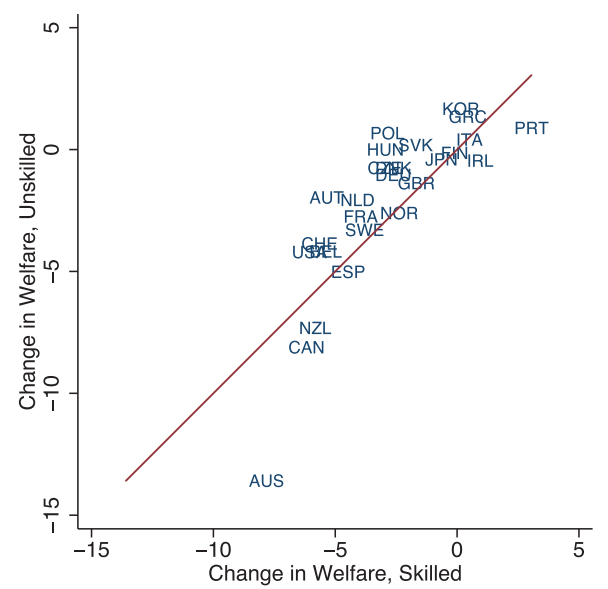

(a) OECD Countries, Long Run

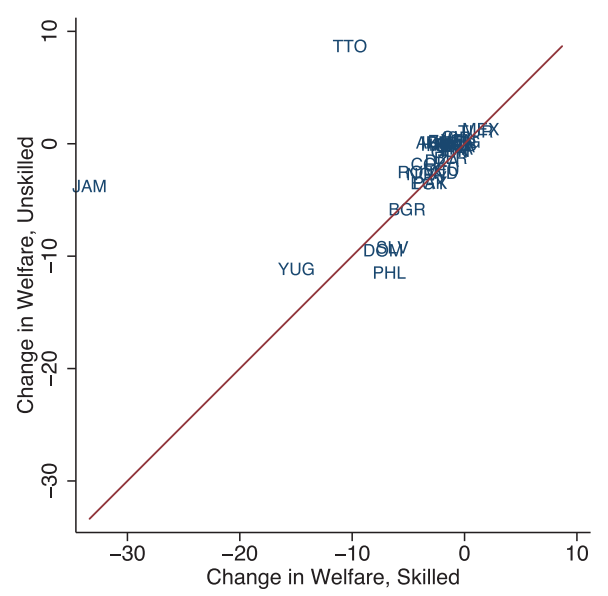

(c) Non-OECD Countries, Long Run

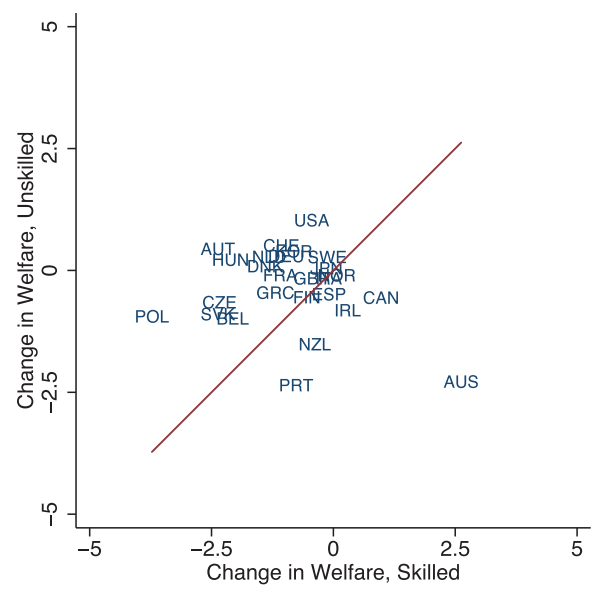

(b) OECD Countries, Short Run

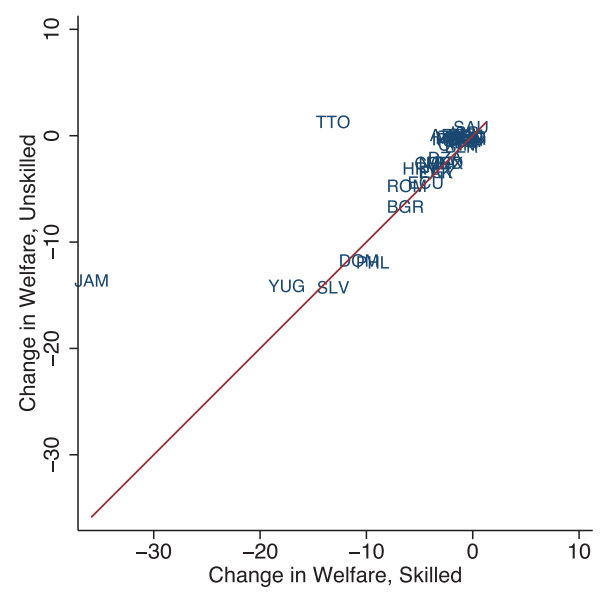

(d) Non-OECD Countries, Short Run

FIGURE 4. Distributional effects: welfare changes of skilled and unskilled natives. Units on both axes are in percentage points. These figures present scatterplots of the percent change in welfare of the unskilled native stayers against the change in welfare of the skilled native stayers, for the OECD (top half) and the non-OECD (bottom half) countries respectively, in both the long run (left side) and the short run (right side). The line through the data is the 45-degree line in each plot.

in the aggregate, Australia would be $0.68 \%$ worse off in the absence of migration, unskilled Australians would be $2.28 \%$ worse off, while skilled Australians $2.63 \%$ better off. The identity of winners and losers across countries corresponds closely to the relative skill levels of natives and immigrants. In the United States, immigrants are comparatively unskilled (Table 1), and thus in the short run migration benefits the skilled at the expense of the unskilled. The opposite is true for Australia. This is a general pattern: in the short run, the correlation between welfare changes for the 
skilled and the unskilled is negative at -0.22 . (By contrast, in the long run the welfare changes for those two groups are strongly positively correlated at 0.81 .)

For the majority of non-OECD countries, the distributional effects are negligible both in the short run and in the long run. This is intuitive: as discussed previously, for these countries the welfare effects are dominated by remittances, which are the same in the short and the long run. Only a couple of countries-Jamaica and Trinidad and Tobago - exhibit large distributional effects. In these countries, reversing emigration leads to large welfare losses for the skilled among the native stayers, with a much more subdued (or even a positive) impact on the unskilled. Table 2 reveals that emigrants from Jamaica and Trinidad and Tobago are overwhelmingly more skilled than the native stayers. These large disparities, coupled with large observed emigration, imply that returning emigrants home to these countries will significantly change the relative supply of skill there, leading to large distributional effects.

\section{Extensions and Sensitivity}

This section briefly discusses a number of extensions and sensitivity checks on the main results. Online Appendix B describes these exercises in detail.

\subsection{Native-Immigrant Productivity Differences}

Migrant productivity may differ from that of the natives of similar skill levels for a variety of reasons. On the one hand, it is well documented that migrants suffer a reduction in human capital associated with imperfect transferability of skills across countries, at least temporarily. If this is indeed the case, the findings described previously may overstate the effects of migration on the effective labor force (in efficiency units) of the host country. On the other hand, some immigrants may be permanently more productive (i.e., earn higher wages) than natives with similar schooling levels. This could be due to positive selection into migration: migrants may be above-average in terms of unobservable skills (such as talent or ability) relative to individuals that are observationally equivalent in terms of education, work experience, gender, and so on. Of course, negative selection into emigration is also possible, and the type of selection may well vary substantially by origin country. ${ }^{23}$ Online Appendix B.1 presents two approaches to calibrating native-immigrant productivity gaps, and shows that the results are quite similar to the baseline.

\subsection{Imperfect Substitution Between Natives and Immigrants}

The baseline framework assumes that native and immigrant workers in the same skill category are perfect substitutes. Recently, several studies have questioned this

23. Borjas (1987) explores the conditions for one type of selection or the other to take place. 
assumption (Manacorda, Manning, and Wadsworth 2012; Ottaviano and Peri 2012). Online Appendix B.2 implements a model in which natives and immigrants of the same skill level are imperfect substitutes. As expected, assuming imperfect substitutability between immigrants and natives increases the gains from immigration for the typical host country since now natives and immigrants do not compete head to head. The cross-country pattern of welfare changes is very similar to the baseline.

\subsection{Additional Sensitivity and Welfare of Migrants}

We examine the sensitivity of the main results along a number of additional dimensions. First, the key mechanism through which natives in the destination countries gain from migration is increased product variety. Since equilibrium variety responds endogenously to market size, and larger markets exhibit greater equilibrium variety, individuals living in larger markets enjoy greater welfare, all else equal. This phenomenon is often referred to as the "scale effect". Scale effects are common and well studied in both economic growth (e.g., Romer 1990) and international trade (e.g., Krugman 1980). Nonetheless, it is important to justify this type of mechanism in our quantitative exercise, and to benchmark it to existing empirical estimates of scale effects. Online Appendix B.3 (i) compares the magnitude of the scale effect implied by our model to existing empirical estimates, (ii) implements an alternative calibration that targets a scale effect at the bottom of the range suggested in the literature, and (iii) implements a model with explicit congestion effects to counteract the positive effect of country size on income.

Second, it may be that the share of the skilled in the population has a direct effect on TFP. For instance, Jones (2002) and Benhabib and Spiegel (2005) develop theoretical models that feature a positive link between human capital and TFP growth, while Ciccone and Peri (2006), Moretti (2004), and Iranzo and Peri (2009b), among others, provide estimates of these human capital externalities based on subnational evidence. This force may affect the welfare impact of migration because the migrants are frequently less skilled on average than the natives of their destination countries, and more skilled than the staying natives of their origin countries.

Online Appendix B.4 discusses the results of an extension that incorporates this effect. The results for the OECD remain qualitatively unchanged, whereas the conclusions for the non-OECD turn out to be sensitive to the assumption that TFP is not directly affected by the skilled share. Of course this outcome is very much dependent on the specific parameterization we adopted. Since there is considerable uncertainty regarding the nature of the link between the skilled share and TFP, these results should be interpreted with caution. The exercise suggests that this is a potentially important mechanism that should be explored further in future research.

In Online Appendix B.5, we use our baseline model to perform more realistic policy counterfactuals. Specifically, we compute the welfare effects of reducing the stock of immigrants in each country by $10 \%$. We also evaluate the sensitivity of our baseline results to assuming a much lower elasticity of substitution between skilled 
and unskilled labor. Finally, Online Appendix B.6 discusses the welfare impact of migration on the migrants themselves.

\section{Conclusion}

The cross-border movements of people are large relative to the overall population of many countries. This paper develops a global-scale quantitative assessment of the welfare impact of migration in a large cross-section of both sending and receiving countries. Our main finding is that the long-run impact of observed levels of migration is large and positive for the remaining natives of both the main sending countries and the main receiving ones. Relative to the counterfactual scenario in which no migration takes place, some countries in both groups are as much as $10 \%$ better off. Interestingly, while the overall numbers are similar, the salient reason for the welfare changes is different. For the countries with the highest immigration rates (Australia, New Zealand, Canada), migration raises welfare through increased equilibrium variety. For the countries with the highest emigration rates (El Salvador, Jamaica), the staying natives are better off because of remittances. These forces are also at work for all other countries, but the relative strength of each varies substantially. Our findings also suggest that failing to account for the role of remittances would produce a welfare evaluation that would be severely biased for a number of migration-sending countries.

All in all, our analysis provides a fairly positive view of the welfare effects of international migration, both for origin and destination countries. We note, however, that our analysis does not take into account the effects that immigration may have on the provision of public goods and government-mandated redistribution. Implicitly, we are assuming that immigrants contribute to tax revenue and use public services at the same rate as the natives, and that immigrants do not alter the political equilibrium that determines the overall degree of within-country income redistribution. While this may be a reasonable assumption in some countries, it may not apply universally (Dolmas and Huffman 2004; Ortega 2010). Relatedly, our analysis ignores any impact of migration on social capital such as trust or social cohesion. ${ }^{24}$ Incorporating the fiscal, political, and social channels into the quantitative welfare assessments of immigration remains a fruitful avenue for future research.

24. De la Rica, Glitz, and Ortega (2014) provide a comprehensive survey of the economic effects of immigration in Europe, including the fiscal consequences. Alesina and La Ferrara (2002) find that within the United States, individuals living in localities with high ethnic fractionalization and income disparities exhibit less trust. Using a large cross-section of countries, Ortega and Peri (2014) show that immigration does increase ethnic fractionalization, but any negative economic effects of increased fractionalization appear to be more than offset by other sources of gains. 


\section{References}

Alesina, Alberto and Eliana La Ferrara (2002). "Who Trusts Others?" Journal of Public Economics, 85, 207-234.

Alvarez, Fernando and Robert E. Jr. Lucas (2007). "General Equilibrium Analysis of the EatonKortum Model of International Trade." Journal of Monetary Economics, 54, 1726-1768.

Anderson, James and Eric van Wincoop (2004). "Trade Costs." Journal of Economic Literature, 42, 691-751.

Axtell, Robert L. (2001). “Zipf Distribution of U.S. Firm Sizes.” Science, 293(5536), 1818-1820.

Barro, Robert J. and Jong-Wha Lee (2010). "A New Data Set of Educational Attainment in the World, 1950-2010.” NBER Working Paper No. 15902.

Benhabib, Jess (1996). "On the Political Economy of Immigration." European Economic Review, 40, 1737-1743.

Benhabib, Jess and Boyan Jovanovic (2012). "Optimal Migration: A World Perspective." International Economic Review, 53, 321-348.

Benhabib, Jess and Mark M. Spiegel (2005). "Human Capital and Technology Diffusion." In Handbook of Economic Growth, Vol. 1, edited by Philippe Aghion and Steven Durlauf. Elsevier, Chap. 13, pp. 935-966.

Bergin, Paul and Giancarlo Corsetti (2008). "The Extensive Margin and Monetary Policy.” Journal of Monetary Economics, 55, 1222-1237.

Berry, R. Albert and Ronald Soligo (1969). "Some Welfare Aspects of International Migration." Journal of Political Economy, 77, 778-794.

Borjas, George J (1987). "Self-Selection and the Earnings of Immigrants." American Economic Review, 77(4), 531-553.

Borjas, George J. (1995). "The Economic Benefits from Immigration." Journal of Economic Perspectives, 9(2), 3-22.

Chaney, Thomas (2008). "Distorted Gravity: The Intensive and Extensive Margins of International Trade." American Economic Review, 98(4), 1707-1721.

Ciccone, Antonio and Giovanni Peri (2006). "Identifying Human-Capital Externalities: Theory with Applications." Review of Economic Studies, 73, 381-412.

Davis, Donald R. and David E. Weinstein (2002). "Technological Superiority and the Losses From Migration.” NBER Working Paper No. 8971.

De la Rica, Sara, Albrecht Glitz, and Francesc Ortega (2014). "Immigration in Europe: Trends, Policies and Empirical Evidence." Forthcoming in Handbook on the Economics of International Migration, edited by Barry R. Chiswick and Paul W. Miller. Elsevier. Also IZA Discussion Paper 7778.

di Giovanni, Julian and Andrei A. Levchenko (2013). "Firm Entry, Trade, and Welfare in Zipf's World." Journal of International Economics, 89, 283-296.

di Giovanni, Julian and Andrei A. Levchenko (2012). "Country Size, International Trade, and Aggregate Fluctuations in Granular Economies." Journal of Political Economy, 120, 1083-1132.

Dixit, Avinash K. and Joseph E. Stiglitz (1977). "Monopolistic Competition and Optimum Product Diversity." American Economic Review, 67(3), 297-308.

Docquier, Frédéric, B. Lindsay Lowell, and Abdeslam Marfouk (2009). "A Gendered Assessment of Highly Skilled Emigration." Population and Development Review, 35, 297-321.

Docquier, Frédéric, Joël Machado, and Khalid Sekkat (2012). "Efficiency Gains from Liberalizing Labor Mobility." Working paper, Université Catholique de Louvain and Université Libre de Bruxelles.

Docquier, Frédéric, Abdeslam Marfouk, Çağlar Özden, and Christopher Parsons (2010a). "Geographic, Gender and Skill Structure of International Migration." Working paper, Université Catholique de Louvain, World Bank, and University of Nottingham.

Docquier, Frédéric, Çağlar Özden, and Giovanni Peri (2010b). "The Wage Effects of Immigration and Emigration." NBER Working Paper No. 16646. 
Dolmas, Jim and Gregory W. Huffman (2004). "On the Political Economy of Immigration and Income Redistribution." International Economic Review, 45, 1129-1168.

Dustmann, Christian (2003). "Return Migration, Wage Differentials, and the Optimal Migration Duration." European Economic Review, 47, 353-369.

Dustmann, Christian (2008). "Return Migration, Investment in Children, and Intergenerational Mobility: Comparing Sons of Foreign- and Native-Born Fathers." Journal of Human Resources, 43, 299-324.

Dustmann, Christian, Itzhak Fadlon, and Yoram Weiss (2011). "Return Migration, Human Capital Accumulation and the Brain Drain." Journal of Development Economics, 95, 58-67.

Dustmann, Christian and Albrecht Glitz (2014). "How Do Industries and Firms Respond to Changes in Local Labour Supply." Journal of Labor Economics, forthcoming.

Eaton, Jonathan, Samuel S. Kortum, and Francis Kramarz (2011). "An Anatomy of International Trade: Evidence from French Firms." Econometrica, 79, 1453-1498.

Facchini, Giovanni and Anna Maria Mayda (2009). "Does the Welfare State Affect Individual Attitudes toward Immigrants? Evidence across Countries." Review of Economics and Statistics, 91, 295-314.

Facchini, Giovanni, Anna Maria Mayda, and Prachi Mishra (2011). "Do Interest Groups Affect US Immigration Policy?" Journal of International Economics, 85, 114-128.

Facchini, Giovanni and Max Friedrich Steinhardt (2011). "What Drives U.S. Immigration Policy? Evidence from Congressional Roll Call Votes." Journal of Public Economics, 95, 734-743.

Fairlie, Robert W. (2012). "Immigrant Entrepreneurs and Small Business Owners, and Their Access to Financial Capital." Small Business Administration Office of Advocacy Working Paper No. 396.

Ghironi, Fabio and Marc J. Melitz (2005). "International Trade and Macroeconomic Dynamics with Heterogeneous Firms." Quarterly Journal of Economics, 120, 865-915.

Hamilton, Bob and John Whalley (1984). "Efficiency and Distributional Implications of Global Restrictions on Labour Mobility: Calculations and Policy Implications." Journal of Development Economics, 14, 61-75.

Helpman, Elhanan, Marc Melitz, and Yona Rubinstein (2008). "Estimating Trade Flows: Trading Partners and Trading Volumes." Quarterly Journal of Economics, 123, 441-487.

Hendricks, Lutz (2004). "A Database of Mincerian Earnings Regressions." http://www.lhendricks.org/Mincer.htm.

International Monetary Fund (2007). "Directions of Trade Statistics."

Iranzo, Susana and Giovanni Peri (2009a). "Migration and Trade: Theory with an Application to the Eastern-Western European Integration.” Journal of International Economics, 79, 1-19.

Iranzo, Susana and Giovanni Peri (2009b). "Schooling Externalities, Technology, and Productivity: Theory and Evidence from U.S. States." Review of Economics and Statistics, 91, 420-431.

Jones, Charles I. (2002). "Sources of U.S. Economic Growth in a World of Ideas." American Economic Review, 92(1), 220-239.

Kennan, John (2013). "Open Borders.” Review of Economic Dynamics, 16, L1-L13.

Klein, Paul and Gustavo Ventura (2007). "TFP Differences and the Aggregate Effects of Labor Mobility in the Long Run." B. E. Journals in Macroeconomics, 7, 1-38.

Klein, Paul and Gustavo Ventura (2009). "Productivity Differences and the Dynamic Effects of Labor Movements." Journal of Monetary Economics, 56, 1059-1073.

Krugman, Paul (1980). "Scale Economies, Product Differentiation, and the Pattern of Trade." American Economic Review,70(5), 950-959.

Lewis, Ethan (2011). "Immigration, Skill Mix, and Capital Skill Complementarity." The Quarterly Journal of Economics, 126, 1029-1069.

Manacorda, Marco, Alan Manning, and Jonathan Wadsworth (2012). "The Impact of Immigration on the Structure of Wages: Theory and Evidence from Britain." Journal of the European Economic Association, 10, 120-151.

Mayda, Anna Maria (2006). "Who Is Against Immigration? A Cross-Country Investigation of Individual Attitudes toward Immigrants." Review of Economics and Statistics, 88, 510-530. 
Melitz, Marc J. (2003). “The Impact of Trade on Intra-Industry Reallocations and Aggregate Industry Productivity." Econometrica, 71, 1695-1725.

Merkle, Lucie and Klaus F. Zimmermann (1992). "Savings, Remittances, and Return Migration." Economics Letters, 38, 77-81.

Moretti, Enrico (2004). "Workers' Education, Spillovers, and Productivity: Evidence from PlantLevel Production Functions." American Economic Review, 94(3), 656-690.

Ortega, Francesc (2005). "Immigration Quotas and Skill Upgrading." Journal of Public Economics, $89,1841-1863$.

Ortega, Francesc (2010). "Immigration, Citizenship, and the Size of Government." The B. E. Journal of Economic Analysis and Policy, 10, 26.

Ortega, Francesc and Giovanni Peri (2014). "Openness and Income: The Roles of Trade and Migration.” Journal of International Economics, 92, 231-251.

Ortega, Francesc and Javier Polavieja (2012). "Labor-Market Exposure as a Determinant of Attitudes toward Immigration." Labour Economics, 19, 298-311.

Ottaviano, Gianmarco I. P. and Giovanni Peri (2012). "Rethinking the Effect of Immigration on Wages." Journal of the European Economic Association, 10, 152-197.

Pritchett, Lant (2006). Let Their People Come: Breaking the Gridlock on Global Labor Mobility. Center for Global Development, Washington, DC.

Ratha, Dilip and William Shaw (2007). "South-South Migration and Remittances." World Bank Working Paper No. 102.

Rauch, James E. and Vitor Trindade (2002). "Ethnic Chinese Networks in International Trade." Review of Economics and Statistics, 84, 116-130.

Rauch, James E. and Vitor Trindade (2003). "Information, International Substitutability, and Globalization." American Economic Review, 93(3), 775-791.

Romer, Paul M. (1990). "Endogenous Technological Change.” Journal of Political Economy, 98, S71-S102.

The World Bank (2007). "Doing Business Indicators."

Trefler, Daniel (1993). "International Factor Price Differences: Leontief was Right!” Journal of Political Economy, 101, 961-987.

Trefler, Daniel (1995). "The Case of the Missing Trade and Other Mysteries." American Economic Review, 85, 1029-1046.

Yang, Dean (2008). "International Migration, Remittances and Household Investment: Evidence from Philippine Migrants' Exchange Rate Shocks.” Economic Journal, 118, 591-630.

Uy, Timothy, Kei-Mu, Yi, and Jing Zhang (2013). "Structural Change in an Open Economy." Journal of Monetary Economics, 60, 667-682.

\section{Supporting Information}

Additional Supporting Information may be found in the online version of this article at the publisher's website:

Online Appendices for "A Global View of Cross-Border Migration" 